\title{
A place next to Satoshi: foundations of blockchain and cryptocurrency research in business and economics
}

\author{
Lennart Ante ${ }^{1,2}$ (D) \\ Received: 2 December 2019 / Published online: 15 May 2020 \\ (c) The Author(s) 2020
}

\begin{abstract}
Blockchain technology has become an ubiquitous phenomenon. While the topic originated in computer science, the business and economics literature was comparatively slow to pick up on it. To better understand the academic basis, current developments and future research avenues of the discourse, 9672 cited references of 467 blockchain and cryptocurrency articles from the fields of business and economics are gathered from the Web of Science Core Collection and are analyzed. Five major strands of research are identified through factor analysis. They are reviewed and their interrelation is mapped using social network analysis. Research on (I) market efficiency and economics and (II) asset pricing and valuation is relatively mature and focuses on cryptocurrencies, while research on (III) the principles and applications of blockchain technology, (IV) transactions and anonymity and (V) monetary theory and policy lacks maturity. Potential paths for future research are pointed out and in conclusion, it is assessed that this young field of research still leaves plenty of room for manoeuvre. A scientific place next to Nakamoto (2008) is still available for existing, emerging and new research streams.
\end{abstract}

Keywords Distributed ledger · Bitcoin - Informetric analysis · Bibliometric analysis · Social network analysis

\section{Introduction}

Over the last few years, blockchain technology has shown the potential to affect nearly all industries and sectors. While Bitcoin or, more generally, cryptocurrency was only its first application, the underlying blockchain technology offers much wider scope. The special feature of blockchain technology is that it is not an actual invention but 'merely' an intelligent concatenation of existing mechanisms, which include technical mechanisms but also economic incentive models. A wide range of possible applications and their (potential) consequences remain to be researched. While such a technical topic was

Lennart Ante

ante@blockchainresearchlab.org

1 Blockchain Research Lab, Colonnaden 72, Hamburg 20354, Germany

2 Faculty of Business, Economics \& Social Sciences, University of Hamburg, Von-Melle-Park 5, 20146 Hamburg, Germany 
predictably first embraced by computer scientists and engineers, the business, economics and finance literature has since discovered blockchain for itself and has been producing a steady flow of both empirical and theoretical contributions for several years now.

The concept of blockchain and Bitcoin is attributed to Nakamoto (2008), who suggested the use of a currency or digital cash as the first application of the underlying technology to solve the double-spending problem. Since then, the number of technology applications has soared. The literature has expanded to cover the transformation of financial technologies (e.g. Ashta and Biot-Paquerot 2018; Chen et al. 2017; Gomber et al. 2018; Kim and Sarin 2019; Yang and Li 2018) and potential areas of application such as clearing and settlement (e.g. Caytas 2016; Chiu and Koeppl 2019; Fiedler et al. 2018; Tsai et al. 2018), banking and trade finance (e.g. Cocco et al. 2017; Guo and Liang 2016) or crowd-financing through initial coin offerings (ICOs) (e.g. Adhami et al. 2018; Ante et al. 2018; Fisch 2019). For the health care sector, blockchain is being analyzed as a mechanism to secure and to automate data flows (e.g. Esposito et al. 2018; Liang et al. 2018; Yue et al. 2016). Other applications include supply chain management (e.g. Apte and Petrovsky 2016; Francisco and Swanson 2018), digital identity and personal data (e.g. Dunphy and Petitcolas 2018; Zyskind et al. 2015), energy markets (e.g. Andoni et al. 2019; Oh et al. 2017), government and voting (e.g. Atzori 2017; Ølnes et al. 2017), law and contracts (e.g. Governatori et al. 2018; O'Shields 2017), or the sharing economy (e.g. Pazaitis et al. 2017; Sun et al. 2016). Research also deals with digital assets such as Bitcoin and their properties (e.g. anonymity and irreversibility) and markets (e.g. Chaum 2012; Urquhart 2016). The potential for additional research is as widely scattered as the emerging literature. It is therefore worthwhile to identify, summarize and review the literature, to identify potential avenues of research and to understand more precisely the theories and thoughts that underlie the current state of research. While the research on the solution of the double-spending problem and the secure digital transfer of value via the Internet has a longer tradition, academic research on Bitcoin or blockchain unequivocally begins in 2008. This also raises the question of which research streams formed during this period and which prior literature they are based on. Did the emerging streams of research rely on specific literature that already dealt with the blockchain phenomenon or rather on 'established' scientific literature and theories? What is the mixture of these two types of sources for each new stream of research? Knowing the relevant contributions, thoughts, theories, authors and journals will help researchers to optimally prepare, supplement or conceive projects and to identify promising new avenues of research in this comparatively new field, where scholars enjoy great liberty to pursue their personal interest when selecting a research topic.

A systematic analysis of the field of blockchain research is a necessary first step to obtain a fundamental overview and to identify lines of research that may have been neglected or that may hold specific potential. This is done by co-citation analysis in the form of exploratory factor analysis to prevent subjectivity. In addition, it is identified, using social network analysis, how research directions change over time and how they are related to each other. After considering the research streams and the actual articles, a number of gaps in the existing research and, by implication, promising avenues for future research are pointed out.

Note that the term cryptocurrency refers not only to currencies but also to so-called tokens, which can be used for financing purposes or supply chain transparency, for example. The analysis explicitly includes cryptocurrency, not least because the terms blockchain and Bitcoin were used somewhat interchangeably until recently, with early research in this area referring to Bitcoin throughout. 
The paper proceeds as follows: Related work is described in the "Related work" Section. The "Methodology" Section presents the methodology in terms of data collection and analysis. The "Findings on research streams" Section contains the results, providing an initial overview and then going into detail regarding the development of the five identified research streams. "Social network analysis" Section specifically presents the results of the social network analysis. The "Discussion" Section discusses the results, including limitations and future research avenues. Finally, the "Conclusion" Section contains a brief conclusion.

\section{Related work}

The summary, processing and analysis of existing research represents an important task for the further development of scientific discourses. For this purpose, different methodologies are available, such as structured literature reviews or bibliometric studies. Literature reviews are often subject to author bias, while bibliometric studies use quantitative approaches to investigate relationships between relevant characteristics, such as authors, publications, citations or keywords (Tranfield et al. 2003; Zupic and Čater 2015).

A number of literature reviews of the blockchain and cryptocurrency literature focused, for example, on individual application areas of blockchains such as the Internet of Things (Conoscenti et al. 2017; Khan and Salah 2018), the sharing economy (Hawlitschek et al. 2018), service systems (Seebacher and Schüritz 2017), big data challenges (Karafiloski and Mishev 2017), cyber security (Taylor et al. 2019) or e-government (Batubara et al. 2018). Yli-Huumo et al. (2016) present a very helpful, though no longer quite up to date, systematic mapping analysis of the state of blockchain research and Corbet et al. (2019) systematically analyzed cryptocurrencies as financial assets based on 32 empirical publications on the topic. They identified the five thematic areas (1) bubble dynamics, (2) regulation, (3) cybercrime, (4) diversification and (5) efficiency and outlined ten different gaps in the literature (see Table 5 in their study for an overview).

Currently, there are various bibliometric studies on the topics blockchain, cryptocurrency, Bitcoin and/or smart contracts. Liu (2016) collected 253 Bitcoin-related publications from Scopus and applied co-word analysis, finding three groups based on similarities that relate to (1) technological, (2) financial, and (3) legal/regulatory questions. Holub and Johnson (2018) collected Bitcoin-related literature from 22 databases and, after refinement, mapped 1206 papers based on categories and disciplines. They showed that $29.9 \%$ of publications belonged to technology-related categories, while $24.9 \%$ were economics-related and only half of the papers in their sample have been published in journals. The study of Merediz-Solá and Bariviera (2019) used 1162 publications extracted from Web of Science to study research on Bitcoin (excluding blockchain applications). The authors provided an overview of the research environment, analyzed the degree of concentration of variables such as authorship and visualized connections of words in titles and abstracts or journals.

Zeng et al. (2018) based their analysis on 473 blockchain-related papers extracted from EI Compendex (EI) and 497 from the China National Knowledge Infrastructure (CNKI)both engineering-focused databases. The authors analyzed the publications using social network analysis and textual analysis and identified that the topic blockchain has become more important than Bitcoin since 2017. This shift of relevance from Bitcoin to blockchain has also been found in another bibliometric study on the topic that is based on 995 papers from Web of Science (Dabbagh et al. 2019). Miau and Yang (2018) extracted 801 articles from Scopus that related to various blockchain and cryptocurrency search terms. 
They used Lotkas's law and the $\mathrm{K}-\mathrm{S}$ test to derive author productivity and identified distinct phases in the research development, beginning with Bitcoin and cryptocurrencies in $2008 / 09$, followed by rapid literature growth in 2014/15 and, most recently, focusing on blockchain technology and smart contracts after 2016. Firdaus et al. (2019) analyzed the topic blockchain based on 1119 publications between 2013 and 2018 extracted from Scopus. Here, the analysis methods comprised descriptive evaluations, such as rankings and author dominance, and visualizations. The authors state to refer to literature from the year 2013 onwards, as the blockchain was introduced in that year. In fact, blockchain technology was introduced by Nakamoto (2008). Klarin (2020) based his analysis on 174 publications extracted from Scopus, identified the four thematic clusters (1) Bitcoin and cryptocurrencies, (2) blockchain adoption, (3) cryptocurrency and blockchain environment, and (4) business model innovations via co-citation analysis and outlined a detailed overview of future research directions for each cluster. One single bibliometric study focused explicitly on the concept of smart contracts, scripts that are anchored on blockchains. Over 1700 documents extracted from Scopus were analyzed descriptively and trends were identified via word cloud and clustering using the software VOSviewer. Six clusters were identified that deal with (1) smart cards, (2) contracts, (3) smart power grids, (4) blockchain, (5) economics and (6) energy. The authors conclude that there are two trends for research on smart contracts: e-commerce and smart power grids (Salmerón-Manzano and ManzanoAgugliaro 2019).

While research in the areas of cryptocurrency and blockchain has already been examined in the context of various bibliometric publications, the focus of the investigations has been, at least to a large extent, on performance analysis, i.e. the evaluation of scientific performance of authors or institutions (Zupic and Čater 2015). The approach of uncovering the intellectual structures and dynamics of research fields (science mapping) via cocitation analysis was only done by few studies using the VOSviewer software (e.g. Klarin 2020; Miau and Yang 2018). The aim of this work is to uncover the intellectual structure of blockchain and cryptocurrency literature in business and economics by empirically analyzing the research field via co-citation analysis using exploratory factor analysis, which has been widely used to identify research streams in bibliometric data (e.g. Kuntner and Teichert 2016; Nerur et al. 2008; Wörfel 2019; Zuschke 2019)—but not yet for blockchainrelated topics. This allows to reduce complexity for researchers by providing an objective overview and review of the most important research streams and their publications in the field of blockchain and cryptocurrency. Furthermore, this study differs from existing studies in that it explicitly focuses on the business and economics literature.

\section{Methodology}

The data were collected from the Web of Science Core Collection in July 2019. To capture all publications on blockchain and cryptocurrencies, the search term $T S=($ blockchain* OR distributed ledger* OR cryptocurrenc* OR bitcoin $*$ ) is used. Only peer-reviewed articles in the fields of business, finance and economics published after 2007 were considered. The extracted sample comprised 494 articles. (Without the discipline constraint, 2132 articles were obtained, with computer science and engineering accounting for most of the additional papers.) 27 articles proved to be unrelated to blockchain and cryptocurrency, so the final record contains 467 articles, with references to 9672 sources. These sources then 
naturally also refer to dates prior to 2008 and only a part of them are peer-reviewed publications. The final list of the 467 articles can be retrieved under https://doi.org/10.17632/ x 5 cstsscmz.1.

This paper relies on co-citation analysis. Co-citation occurs when two articles simultaneously feature in the bibliography of a third article, which means that the first two articles must precede the article that cites them. This temporal relationship can help to identify the academic basis of research results. A higher co-citation frequency is typically interpreted to indicate greater relevance of an article within a given research stream (Small 1973, 1977). For the analysis, the extracted references were compiled in a square similarity matrix, whose diagonal values are replaced by the mean value of the respective column (McCain 1990; Small 1973). For this purpose, the data extracted from Web of Science is processed using the Bibexcel toolbox for bibliometricians (Persson et al. 2009), which allows easy subsequent use for factor analysis using SPSS and social network analysis using UCINET (Borgatti et al. 2002). A cutoff value of three co-citations was selected for the purpose of co-citation matrix creation, which resulted in a sample consisting of the 202 publications with three or more co-citations. Bibliometric data is usually highly skewed, which means that a comparatively small but highly important part of the literature contains most of the achievements in a particular field (Chen and Leimkuhler 1986). A bibliometric analysis therefore need not examine all articles cited in a discipline; it suffices to analyze the most widely-cited ones.

The analysis of the co-citation data relies on exploratory factor analysis. Factor analysis is a static method that allows to extract underlying structures from a data set by identifying relationships between variables. It provides a suitable method of analysis when there are no hypotheses regarding the structure of a data set prior to an investigation. Since a symmetrical co-citation matrix contains the number of co-citations for each article, the articles can be divided into contiguous groups or factors by means of factor analysis. If we assume that a multitude of similar sources for research work implies similar ideas and mindsets, these factors represent scientific discourses or streams of research. Within the framework of factor analysis, a correlation matrix is first generated from a data matrix, which then becomes a factor matrix. The research streams are distinguished from factors that are not considered further on the basis of a sharp decline in the eigenvalues associated with the factors, assessment of the generated scree plot and the respective percentage of variance explained. In addition, further factors in the analysis output include so few articles that they cannot be described as an individual strand of research. Factors are initially identified though principle component analysis, which extracts the highest variance of the data set and assigns the first factor to it. This process is then continued until a final factor with the proportionally smallest variance has been determined. Factors are then 'rotated' to distribute the extent of variability more uniformly between factors. Factors loadings are thus redefined so that they are relatively high $(-1$ or 1$)$ or low $(0)$. This allows for a better differentiation between factors and the analysis derived from it. Factor loadings are generated via Varimax rotation with Kaiser normalization, as communalities between items are high (Kaiser 1959). They represent numerical values that indicate the strength and orientation of a factor to a measured variable - in this case a measure of the thematic fit of a particular publication to a research stream. A factor loading above 0.4 indicates that an article is part of a factor (i.e. scientific discourse), while a value above 0.7 indicates high relevance (McCain 1990). Besides factor loadings, factor scores are calculated using the regression method, in which the effects of each observation on factors are predicted. The identified values represent the relevance or spacing of an observation with respect to a factor (DiStefano et al. 2009; Gorsuch 1988). Transferred to bibliometric analysis factor scores indicate the contribution that 
an article makes to a research stream (Nerur et al. 2008). An article with a low factor loading and a high factor score does not fit well into a stream, but is nevertheless important to it.

Social network analysis is then used to uncover relationships and dependencies between publications and research streams. The relationships among individual articles are visualized in a two-dimensional plane using the UCINET NetDraw algorithm. This is done on the basis of intellectual proximity, which is determined by the number of co-citations (Biehl et al. 2006). A final set of coordinates is determined by arranging Euclidean distances in relation to the geodesic distance between nodes, in this case publications (Carrington et al. 2005). A map of the research clusters is thus obtained that reveals the relationships among them and indicates the relevance of individual articles by the size of the nodes.

\section{Findings on research streams}

Table 1 provides an overview of the identified streams of research and further statistics. It is shown how publications are distributed over the five factors determined through factor analysis. Only the highest factor loading is considered, i.e. if an observation has factor loadings above 0.4 for several factors, only the highest one is assigned. Through factor analysis, five different discourses are identified, which together account for $63.08 \%$ of the total variance in the sample. In this context, variance signals the relevance of a research stream for the entire research environment (Nerur et al. 2008). Specifically, principal component analysis and the varimax rotation method with Kaiser normalization are used. The rotation converged after 29 iterations. A Kaiser-Meyer-Olkin (KMO) measure of 0.851 and a highly significant Bartlett test statistic $(p<0.001)$ are obtained. These test statistics apply to each of Tables 1, 2, 3, 4, 5, 6 and 7 and are therefore not repeated. Factor analysis thus proves to be a suitable method of analysis.

The first and largest strand of research deals with the market economics and efficiency of cryptocurrencies. It accounts for $36.65 \%$ of the variance in the sample and a percentage of $35.6 \%$ of all examined publications can be assigned to the stream, of which more than half have factor loadings above 0.7 and thus represent publications of high thematic fit. The second stream (12.15\% of the variance) concerns asset valuation and price formation and consists of $26.4 \%$ of all articles (9.2\% with factor loadings above 0.7$)$. The third stream accounts for $5.52 \%$ of the variance and deals with the principles and applications of blockchain. A share of $12.1 \%$ of papers can be assigned to the stream, while $5.7 \%$ of the sample represent important publications. The fourth stream $(5.04 \%)$ covers special properties of cryptocurrency transactions, such as anonymity or irreversibility, and their regulatory implications. It covers $8.6 \%$ of all publications analyzed in the factor analysis and has the smallest share of high-fit publications (3.4\%). Lastly, the fifth stream accounts for $3.73 \%$ of the variance and deals with monetary theory and policy, such as the suitability of Bitcoin as a currency. It represents a share of $7.5 \%$ of all papers examined, of which $75 \%$ are highly relevant publications for the stream.

The Bitcoin whitepaper (Nakamoto 2008) is the scientific basis of blockchain and cryptocurrency research. Its factor loading and factor score with respect to each of the five discourses are shown in Table 1. Based on the factor loading, the whitepaper is most closely affiliated with stream II (0.487), with stream I in second place (0.456). Based on the factor score, the whitepaper is highly relevant to streams III (9.751) and IV (3.167). Its relevance 


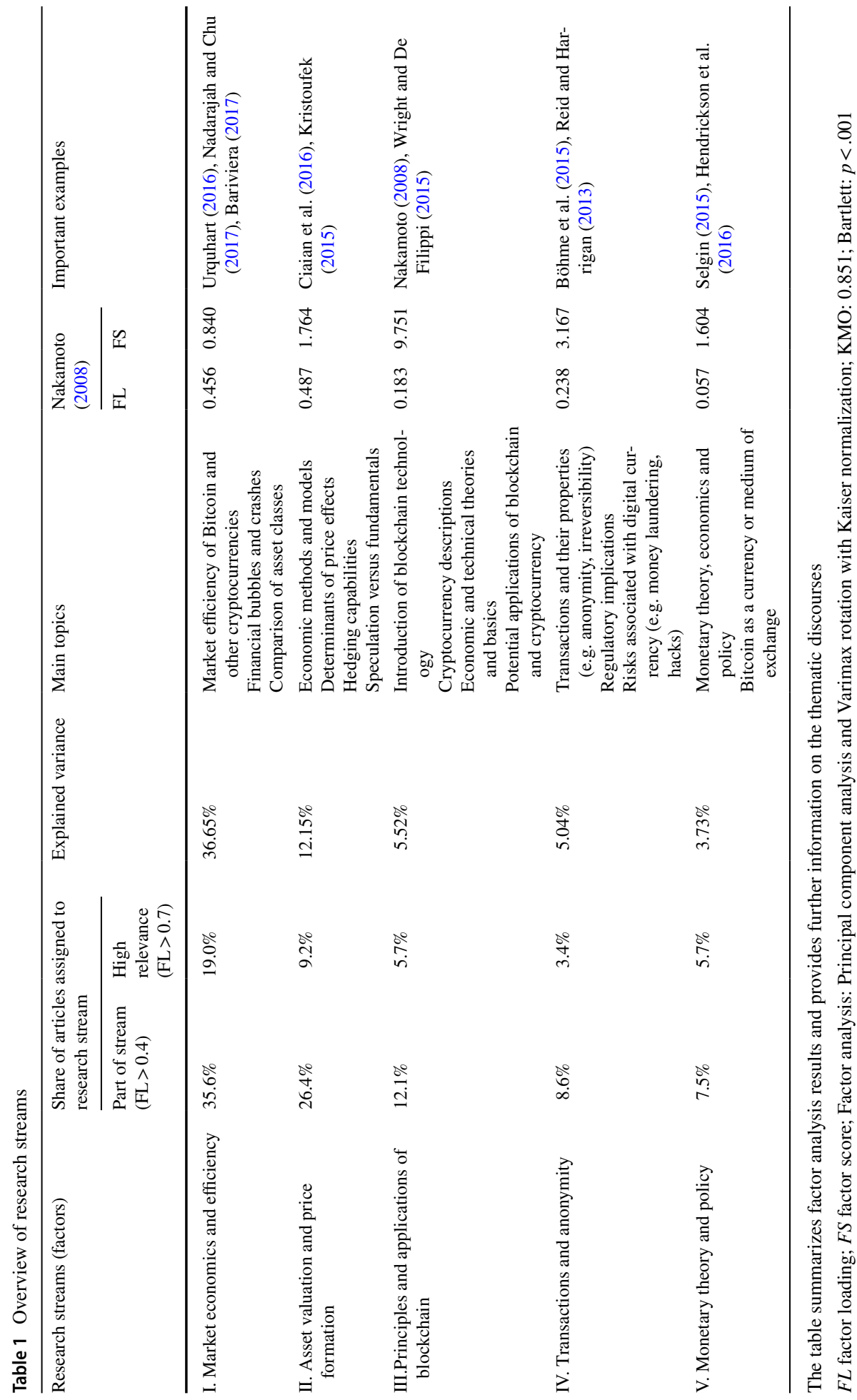


Table 2 Correlation between the factors

\begin{tabular}{lccccc}
\hline Research streams (factors) & I & II & III & IV & V \\
\hline I. Market economics and efficiency & 1.00 & & & & \\
II. Asset valuation and price formation & -0.07 & 1.00 & & & \\
III. Principles and applications of blockchain & -0.27 & -0.05 & 1.00 & & \\
IV. Transactions and anonymity & -0.04 & 0.11 & 0.06 & 1.00 \\
V. Monetary theory and policy & -0.12 & -0.27 & -0.01 & -0.07 & 1.00 \\
\hline
\end{tabular}

Factor analysis: Principal component analysis and Oblimin rotation with Kaiser normalization

is somewhat lower for research on asset valuation and price formation, and monetary theory and policy. The relevance of Nakamoto (2008) is lowest with respect to stream I.

Figure 1 shows histograms of the distribution of factor loadings and factor scores for all five identified research streams. It can be seen that the distribution of factor loadings in streams I and II varies comparatively strongly, while a trend can be observed in the three following streams. There, the largest part of all loadings is found between -0.1 and 0.1 , which shows that factors are composed of only a few specific publications and that the majority of the remaining ones are hardly thematically related. Stream IV represents a special feature, which is expressed by the fact that the highest identified factor loadings is 0.78. In terms of factor scores, stream III with has an extremely high factor score of 9.75 .

Table 2 shows the correlation coefficients among the five factors or research streams, as obtained via oblique rotation. Factors one and five exhibit negative coefficients throughout. The strongest positive correlation exists between streams II and IV, while the strongest negative correlation applies to the relationships between streams I and III, and II and V, respectively. This suggests that streams I and III as well as streams II and IV have little in common, while streams II and V have high similarity.

Figure 2 shows the relative development of the research streams over time based on the number of publications. For this purpose, every publication with more than three cocitations was assigned to one of the five streams or 'other', and the relative size of the six categories was graphed for each year or period.

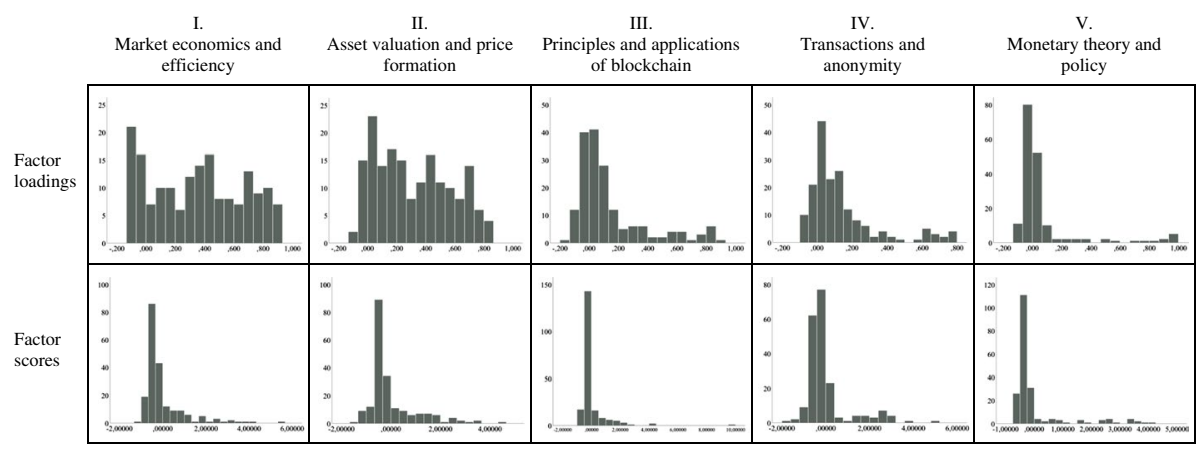

Fig. 1 Distribution of factor loadings and factor scores across research streams. Frequencies are displayed on the $\mathrm{y}$-axis, factor loadings and factor scores on the $\mathrm{x}$-axis respectively 


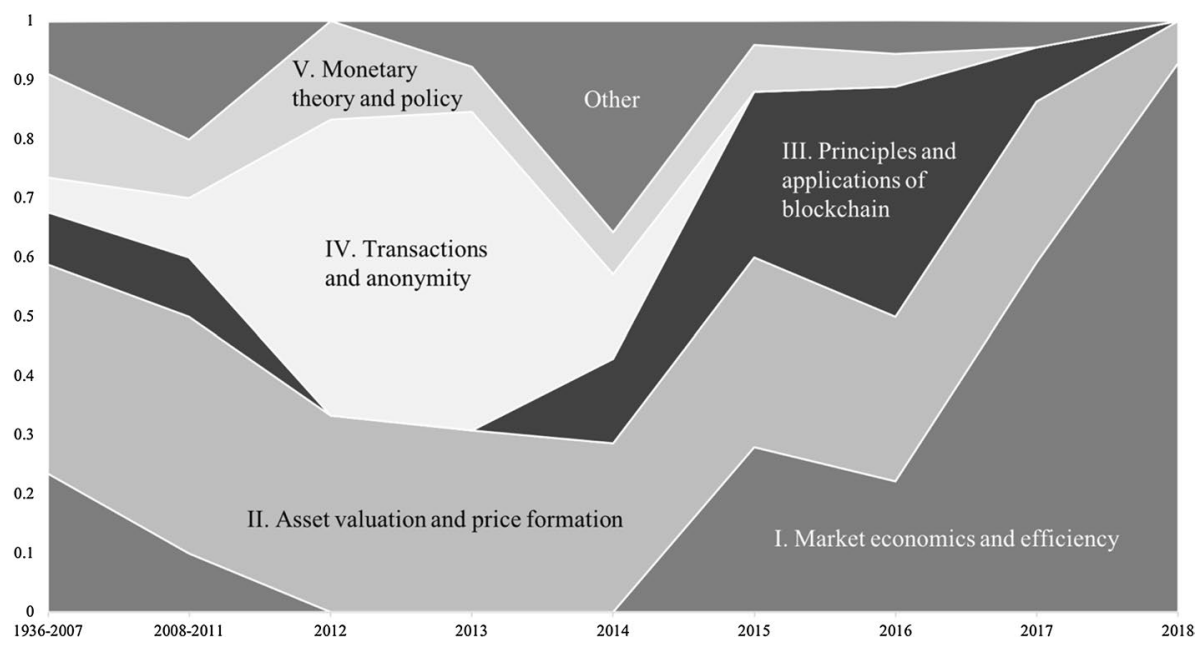

Fig. 2 Relative development of research stream publications over time

Note that the years before the publication of the Bitcoin whitepaper were grouped into a single period, as were the years 2008 to 2011 , because of the very low number of publications prior to 2012. Research stream I has been gaining ground steadily since 2014 and by 2018 accounted for $92.3 \%$ of the research on blockchain and cryptocurrencies examined here. The streams on 'transactions and anonymity' and 'monetary theory and policy' hit their peak importance in the period 2012 to 2014, while 'blockchain basics' peaked in 2015/16. Stream II accounted for a consistently large share.

The following subsections describe each of the research streams in detail before their interrelations are analyzed via social network analysis.

\section{Market economics and efficiency}

The first research stream comprises 33 articles, explains $36.65 \%$ of the variance and deals with the economics and efficiency of cryptocurrency markets, with most studies focusing on Bitcoin. The overall aim of the discourse is to promote the understanding of cryptocurrency markets. The ten most relevant publications within the stream and their factor loadings and scores are shown in Table 3. The distribution of publications across journals is presented below the table. Economics Letters has the highest number of publications in this field, followed by Finance Research Letters. This stream of research is heavily based on theories of market efficiency, so it comes as no surprise that besides cryptocurrencyspecific articles, basic literature on capital market efficiency (Fama 1970) or portfolio theory (Markowitz 1952) also shows up in this stream. Many of the publications in this stream are scientific letters and research notes, which build upon or reply to each other. The vast majority of the publications date from 2017/18.

The study by Donier and Bouchaud (2015) deals with the efficiency of the Bitcoin market and tests various liquidity measures as early warning signs of a bitcoin crash. Urquhart (2016) has the highest factor score (5.565), which suggests the greatest relevance for this research stream. The author uses a number of tests to identify autocorrelation for Bitcoin 
Table 3 Articles on market efficiency of cryptocurrency

\begin{tabular}{lll}
\hline Article & Factor loading & Factor score \\
\hline Tiwari et al. (2018) & 0.907 & 2.969 \\
Bariviera (2017) & 0.899 & 3.352 \\
Urquhart (2018) & 0.893 & 1.137 \\
Yonghong et al. (2018) & 0.884 & 1.717 \\
Urquhart (2017) & 0.878 & 2.547 \\
Brauneis and Mestel (2018) & 0.871 & 1.275 \\
Nadarajah and Chu (2017) & 0.870 & 4.214 \\
Kristoufek (2018) & 0.864 & 0.723 \\
Phillip et al. (2018) & 0.860 & 1.438 \\
Katsiampa (2017) & 0.852 & 3.857 \\
$\ldots$ & $\ldots$ & $\ldots$ \\
Urquhart (2016) & 0.807 & 5.565 \\
Other: 22 publications with factor loading $\geq 0.714$ &
\end{tabular}

This table shows factor loadings and factor scores of the most important publications assigned to research stream I (the first factor obtained through factor analysis)

Distribution across journals: Economics Letters (15 articles); Finance Research Letters (8); Physica A (3); Journal of International Financial Markets, Institutions \& Money (2); Chaos, Solitons \& Fractals; Economic Modelling; International Review of Financial Analysis; Journal of Finance; Journal of Monetary Economics (1 each).

prices and finds that it persists over the entire observation period (Aug 2010 to Jul 2016). When the period is divided into two phases, however, it turns out that the first phase is responsible for the autocorrelation effect. Nadarajah and Chu (2017) examine the same data set again with the help of power transformations of daily returns and find no such effect. Fry and Cheah (2016) point out the speculative component of cryptocurrency markets and model financial bubbles and crashes. The authors analyze these markets by means of econophysics models and find evidence of spillover effects from Ripple to Bitcoin. Bouri et al. (2017) investigate the volatility of Bitcoin returns before and after the market crash in 2013 due to the collapse of the Mt.Gox exchange and find serial correlation. Corbet, Lucey, et al. $(2018 \mathrm{a}, \mathrm{b})$ analyze potential price bubbles in Bitcoin and Ethereum and conclude that there are periods with clear bubble behaviour-with Bitcoin being in a bubble phase when the paper was published. Kristoufek (2018) shows that in cool-down periods directly after bubbles or price surges, the Bitcoin market becomes efficient, while it remained inefficient for most of the period 2010 to 2017.

The Bitcoin market exhibits time frames that are efficient and ones that are driven by anti-persistence (Alvarez-Ramirez et al. 2018). The paper by Bariviera (2017) has the second highest factor loading $(0.899)$ in the research stream and furthermore has a high factor score of 3.352. The study analyzes daily Bitcoin price data from 2011 to 2017 using two variations of the Hurst exponent, a metric that characterizes the scaling behavior of the cumulative deviations from the mean of a time series (Hurst 1951). The results show that daily returns behave consistently during the first part of the observation period, while the dimension of informativity increases from 2014. The volatility of the Bitcoin price exhibits long memory for the full observation period. Comparing the explanation of volatility by different GARCH models, Katsiampa (2017) shows that both short-run and long-run components of conditional variance are important for a suitable model. The investigation of 
nonlinear patterns of volatility in Bitcoin markets suggests long-term memory and provides strong evidence against the efficient market hypothesis (Lahmiri et al. 2018). Cheah et al. (2018) find long memory and cointegration in Bitcoin markets, with a negative correlation between cointegration and uncertainty.

The study with the highest factor loading, Tiwari et al. (2018), is an extension to Urquhart (2016), Nadarajah and Chu (2017) and Bariviera (2017), and confirms the earlier result that the Bitcoin market is informationally efficient. While most previous studies only considered Bitcoin, Brauneis and Mestel (2018) expand this focus by testing the efficiency of nine additional cryptocurrencies and conclude that higher liquidity leads to reduced efficiency. Similarly, Wei $(2018 \mathrm{a}$, b) examines the liquidity of 456 cryptocurrencies and shows that greater market capitalization reduces the predictability of market behavior. The author concludes that liquidity is a significant factor for the market efficiency of cryptocurrencies. Corbet et al. (2018a, b) find that across different cryptocurrencies, investors with a short investment horizon may gain diversification benefits. By some degree of contrast, empirical findings by Ciaian et al. (2018) suggest that Bitcoin and Altcoin (non-Bitcoin cryptocurrencies; in this case, 16 of them) markets are interdependent.

Phillip et al. (2018) analyze 224 different cryptocurrencies and identify unique properties, like stochastic volatility, Student-t error distributions and leverage effects. Studying the tail behavior of the five largest cryptocurrencies and using value-at-risk and expected shortfall as risk metrics, Gkillas and Katsiampa (2018) find that Bitcoin Cash is the riskiest asset, while Bitcoin and Litecoin have the lowest risk.

Urquhart (2017) studies price clustering of Bitcoin, finding that prices are clustered at round digits. In addition, price and trading volume have a significantly positive relationship with price clustering around round digits, which confirms Harris' (1991) negotiation hypothesis. Urquhart (2018) examines the relationship between Bitcoin fundamentals and the attention of investors. Realized volatility and trading volume are found to drive the next-day attention for bitcoin. The study has a relatively low factor score (1.137) compared to the other publications in the top ten, which suggests a lower overall relevance for the discourse.

Other studies in this research stream address the question whether Bitcoin is a medium of exchange or an asset. Dyhrberg (2016a), Bariviera et al. (2017) and Baur et al. (2018a, b) compare currency dynamics to Bitcoin, while Baur et al. (2018a, b) find that Bitcoin is not correlated with traditional asset classes (stocks, bonds and commodities)—regardless of market timing. The authors analyze transaction data and suggest that Bitcoin is used as a speculative investment. In comparison to foreign exchange markets, Bitcoin has narrower bid-ask spreads, resulting in favorable exchange rates due to its simpler infrastructure (Kim 2017).

\section{Asset valuation and pricing}

The second research stream accounts for $12.15 \%$ of the variance. This stream is somewhat similar to the first one, not least with regard to its set of contributors. In comparison to stream I, however, the publications are older, and several articles do not explicitly refer to cryptocurrencies but merely provide a basis for such studies. The overall theme of the stream can be summarized as asset valuation and price formation. The discourse tackles the question of how cryptocurrency prices can be explained and determined. The ten most important publications of the stream based on factor loadings are presented in Table 4. 
Table 4 Articles on asset valuation and price formation

\begin{tabular}{lll}
\hline Article & Factor loading & Factor score \\
\hline Engle (2002) & 0.825 & 1.642 \\
Hayes (2017) & 0.814 & 1.545 \\
Bouoiyour and Selmi (2015) & 0.812 & 1.169 \\
Yermack (2015) & 0.795 & 0.633 \\
Bouoiyour et al. (2016) & 0.793 & 0.700 \\
Baur and Lucey (2010) & 0.771 & 2.610 \\
Kristoufek (2015) & 0.759 & 3.330 \\
Rogojanu and Badea (2014) & 0.743 & 1.168 \\
Glosten et al. (1993) & 0.735 & 1.438 \\
Ciaian et al. (2016) & 0.726 & 4.537 \\
Other: 2 publications with factor loading $\geq 0.712$ & \\
\hline
\end{tabular}

This table shows factor loadings and factor scores of the most important publications assigned to research stream II (the second factor obtained through factor analysis)

Distribution across journals: one article each in Annals of Economics and Finance; Applied Economics; Economics Bulletin; Financial Review; Journal of Banking \& Finance; Journal of Business and Economic Statistics; Journal of Finance; PLoS ONE; Telematics and Informatics; The Quarterly Review of Economics and Finance; Theoretical and Applied Economics; plus one book chapter.

There is no trend regarding the outlets of publication, as all twelve papers were published in different journals.

The article with the highest factor loading, Engle (2002), is a methodology paper that introduced a new form of multivariate GARCH models - dynamic conditional correlation models - as an estimation technique. This illustrates the relevance of GARCH models in the analysis of crypto markets and the large number of formal and theoretical models in this research stream. Another major methodological paper, Glosten et al. (1993), ranks 9th in the stream with a factor loading of 0.735 . Using a GARCH-M model, the study finds support for negative relationships between conditional expected monthly returns and the conditional variance of monthly stock returns: Positive expected returns are associated with a downward revision of conditional volatility, and vice versa. Baur and Lucey (2010) analyze the suitability of gold as a hedge against stocks and bonds. The study is an empirical and theoretical basis for similar research (e.g. Bouri et al. 2017; Dyhrberg 2016b) that is later conducted on cryptocurrencies but which is assigned to research stream I.

Yermack (2015) investigates whether Bitcoin is a real currency. The author notes that currencies are a medium of exchange, a store of value and a unit of account, but Bitcoin did not fulfil these functions at the time (2013). Its daily trading statistics are uncorrelated with established currencies or gold. Against this background and Bitcoin's various risks, such as hacks, theft or lack of access to the financial system, the author considers Bitcoin as a speculative investment rather than a currency. By contrast, Bouoiyour et al. (2016) classify Bitcoin as driven by long-term fundamentals (above one year). This is the result of a study using Empirical Mode Decomposition (EMD), where a data set is divided into several smaller independent data sets.

Using ARDL bounds testing, Bouoiyour and Selmi (2015) investigate the main determinants of the Bitcoin price. They find Bitcoin to be subject to extensive speculation and to 
be suitable to some extent as a basis for transactions of value on the Internet. The authors conclude that Bitcoin is a highly speculative asset, which prevents its wider use. Kristoufek (2015) analyses determinants of the Bitcoin price and effects of the Chinese market using a continuous wavelet framework and finds that fundamental values such as trading volume, 'money' supply and price level play a long-term role. A rising Bitcoin price attracts new miners. However, this effect declines over time as technology and mining processes become more professional. The price of Bitcoin depends on investor interest, which is particularly evident during price spikes. Another study of Bitcoin price formation finds that market forces and the attractiveness for investors have significant effects on Bitcoin prices, but the effects vary over time (Ciaian et al. 2016). Hayes (2017) investigates the explanatory factors for value formation in a cross-section of 66 cryptocurrencies, finding three primary factors: the degree of competition in mining, the technical complexity of the mining algorithm and the rate of inflation.

\section{Principles and applications of blockchain}

The third research stream comprises 10 articles, which together account for $5.52 \%$ of the variance. The factor loadings and factor scores of these articles are shown in Table 5. The table additionally contains the Bitcoin whitepaper (Nakamoto 2008), which with a factor score of 9.751 is exceedingly relevant to the discourse. In principle, the articles deal with economic theory and economic and technical fundamentals of blockchain technology. Additionally, potential application areas or specific cryptocurrencies are introduced and discussed.

The third research stream consists of publications that explain blockchains by (1) providing general introductions and highlighting the potential of the technology (Iansiti and Lakhani 2017; Swan 2015; Tapscott and Tapscott 2018; The Economist 2015), (2)

Table 5 Articles on principles and applications of blockchain

\begin{tabular}{lll}
\hline Article & Factor loading & Factor score \\
\hline Tapscott and Tapscott (2018) & 0.880 & 4.280 \\
The Eeconomist (2015) & 0.862 & 1.396 \\
Wood (2014) & 0.843 & 1.060 \\
Iansiti and Lakhani (2017) & 0.831 & 1.574 \\
Szabo (1997) & 0.823 & 0.411 \\
Coase (1937) & 0.819 & 1.398 \\
Swan (2015) & 0.802 & 4.066 \\
Wright and De Filippi (2015) & 0.799 & 2.413 \\
Jensen and Meckling (1976) & 0.768 & 1.619 \\
Lamport et al. (1982) & 0.758 & 1.646 \\
$\ldots$ & $\ldots$ & $\ldots$ \\
Nakamoto (2008) & 0.183 & 9.751 \\
\hline
\end{tabular}

This table shows factor loadings and factor scores of the most important publications assigned to research stream III (the third factor obtained through factor analysis)

Distribution across journals: one article each in Harvard Business Review, The Economist, First Monday, Econometrica, Journal of Financial Economics, ACM Transactions on Programming Languages and Systems (TOPLAS); plus two books, two project whitepapers and one working paper. 
introducing specific cryptocurrencies or blockchains, like Bitcoin (Nakamoto 2008) or Ethereum (Wood 2014), and (3) describing specific applications (of blockchain) on a conceptual, technical or economic level-especially the concept of smart contracts, i.e. the decentralized execution of computer protocols (Szabo 1997; Wright and De Filippi 2015). Economic theories and mechanisms (Coase 1937; Jensen and Meckling 1976; Lamport et al. 1982) form an important theoretical basis for the discourse.

Coase (1937) explains why individuals seek to form partnerships and companies, rather than entering into bilateral contracts on the open market. Transaction costs-those associated with searching, information, negotiation or confidentiality-mean that some services cost more than they are worth. Coase' theory of the firm states that enterprises are formed specifically to reduce such costs. Blockchain being a technology for peer-to-peer transactions of value, the relevance of the theory becomes immediately clear. Jensen and Meckling (1976) provide an extension with their theory of corporate ownership based on property rights theory, agency theory and finance theory. The authors show that while a $100 \%$ owner of a company makes decisions to maximize his own benefit, as soon as external capital flows into the company, the ensuing incentive conflict gives rise to agency costs. The owner no longer bears the full costs of the non-pecuniary benefits he grants himself. This results in agency costs, which materialize as monitoring, economic bonding or residual loss. The third major non-blockchain paper in this research stream is Lamport et al. (1982), who deal with the Byzantine Generals Problem, a theoretical situation where a group of generals can only communicate through messengers. However, some generals may be traitors who spread false information for confusion. The aim is to ascertain which information can be trusted. The solution requires a two-thirds majority of honest generals. The study provides a theoretical basis for consensus mechanisms and an alternative to the proof-ofwork mechanism that Bitcoin uses. The extended mechanism of Practical Byzantine Fault Tolerance (PBFT) (Castro and Liskov 1999) is used by various blockchain infrastructures today.

Nakamoto (2008) provided the theory underlying blockchain technology and Bitcoin. The article is frequently cited and highly relevant in the field of blockchain-specific literature, as reflected by its extremely high factor score of 9.951. The author combined various existing technologies, such as time-stamping (Bayer et al. 1993; Haber and Stornetta 1990, 1997; Massias et al. 1999) and announcements (Dai 1998) of transactions, proof-ofwork (Back 2002), merkle trees (Merkle 1980) and economic incentive systems in a single mechanism to solve the double-spending problem and thus created the basis for today's concept of blockchain technology.

Following Buterin (2013), Wood (2014) introduced Ethereum, to date the second largest public blockchain infrastructure. Ethereum's main goal is to enable smart contracts, autonomous decentralized computer code that is executed on the blockchain. The blockchain uses proof-of-work, which was first introduced by Dwork and Naor (1992), before Back (2002) and Vishnumurthy et al. (2003) applied it to secure a currency. Besides Bitcoin, the Ethereum whitepaper mentions prior cryptocurrency implementations that were discussed in the academic literature, including Litecoin, Primecoin and Namecoin (Aron 2012; Sprankel 2013). Szabo (1997) provides a formal introduction to smart contracts; Miller (1997) made additional early contributions to the field. Wright and De Filippi (2015) take up the concept of smart contracts and show how self-executing digital contracts or smart property can be implemented with the help of blockchain. The authors also describe how this can in theory lead to decentralized autonomous organizations (DAOs), which could fundamentally change the nature of today's central authorities and entities. 


\section{Transactions and anonymity}

The fourth research stream consists of 10 articles and explains $5.04 \%$ of the variance. These ten publications are listed in Table 6 along with 3 additional papers with high factor scores. This research stream primarily deals with the fundamental properties of cryptocurrency, in particular transactions, irreversibility and (pseudo-)anonymity, and their consequences. This includes for example the possibility of secure online peer-to-peer payment or the risks associated with digital currency, such as money laundering. Potential solutions and regulatory approaches are discussed. Most of the publications are from the period 2012 to 2014 and cover either legal or technical aspects. No two papers were published in the same outlet, as shown below the table.

One article in the research stream is from pre-Bitcoin times: Dai (1998), referenced in Nakamoto (2008), which in turn has a high factor score of 3.167 and is therefore a formative source for this research stream, to which however it cannot be assigned due to the comparatively low factor loading of 0.238. Dai (1998) describes the design of a potential digital currency called b-money, which already exhibits many similarities to Bitcoin. Like the Bitcoin whitepaper, the paper by Eyal and Sirer (2014), which analyzes mining and potential vulnerabilities, also has a high factor score (3.138) but does not quite fit into the stream based on its factor loading. Böhme et al. (2015) provide an overview of Bitcoin's economic, technological and governance aspects. Both studies thus provide basic background information on the Bitcoin network.

Table 6 Articles on transactions and anonymity

\begin{tabular}{lll}
\hline Article & Factor loading & Factor score \\
\hline Bryans (2014) & 0.780 & 2.620 \\
Maurer et al. (2013) & 0.760 & 2.250 \\
Krugman (2013) & 0.758 & 1.770 \\
Dai (1998) & 0.752 & 1.430 \\
Ober et al. (2013) & 0.747 & 2.450 \\
Reid and Harrigan (2013) & 0.720 & 2.770 \\
Chaum (2012) & 0.685 & 2.530 \\
Meiklejohn et al. (2013) & 0.678 & 1.410 \\
Ron and Shamir (2014) & 0.662 & 3.820 \\
Stokes (2012) & 0.645 & 2.520 \\
$\ldots$ & $\ldots$ & $\ldots$ \\
Eyal and Sirer (2014) & 0.614 & 3.138 \\
Böhme et al. (2015) & 0.287 & 5.142 \\
Nakamoto (2008) & 0.238 & 3.167 \\
\hline
\end{tabular}

This table shows factor loadings and factor scores of the most important publications assigned to research stream IV (the fourth factor obtained through factor analysis)

Distribution across journals: one article each in Indiana Law Review; Social Semiotics; New York Times; Future Internet; Security and Privacy in Social Networks; Proceedings of the 2013 conference on Internet measurement; Information and Communications Technology Law; Eighteenth International Conference on Financial Cryptography and Data Security, Whitepaper; Journal of Economic Perspectives; plus one website and one book. 
Bryans (2014) approaches money laundering and Bitcoin from a legal perspective, concluding that Bitcoin is a disruptive financial technology which poses major difficulties for established entities in the area of payment processing. New legislation will have difficulties covering digital currency, as its technological development is too far-reaching. The author points out in particular that the lack of oversight is no reason to prohibit Bitcoin and similar currencies. Regulation should only intervene once the law can effectively punish offenders. This is particularly the case for cryptocurrency exchanges, which represent the interface between fiat and digital currencies, as decentralized technology itself cannot be regulated. Stokes (2012) also deals with money laundering and digital currency, examining the cases of Bitcoin and the Linden dollar, a digital currency in the online multi-player game Second Life.

Maurer et al. (2013) investigate the semiotics of Bitcoin with a focus on its property as an irreversible payment system. They argue that Bitcoin may be an appropriate method for enthusiasts looking for a payment system that ensures privacy and freedom from government or corporate interference. The promise and potential of Bitcoin derives not from the capability of government agencies or from mutual trust but from a cryptographic protocol. To this end, the authors suggest that practical materialism is based on concerns about privacy and values. Bitcoin is a promise that no other currency offers in this form: its value is secured by an algorithm and a peer-to-peer network. Ober et al. (2013), a publication from computer science, discuss Bitcoin and its facilitation of anonymous transactions between users in a network. They demonstrate that the Bitcoin network is a valuable source for empirical research on network structure and dynamics and the associated challenges of anonymity, as well as on payment systems. The authors identify dynamic effects that both enhance and inhibit anonymity. Another study from computer science, Reid and Harrigan (2013), analyzes the Bitcoin network and the degree to which the transactions are anonymous. The authors conclude that all historical transactions are publicly accessible and can be viewed by users by means of appropriate tools. Accounts can be linked and bitcoins can be 'colored' to trace the transaction history. Bitcoin is therefore not a completely anonymous network on the technical level. Similarly, other studies in the stream are written by reputable scientists from the field of cryptography and (also) analyze the nature of Bitcoin transactions and their degree of anonymity (e.g. Chaum 2012; Meiklejohn et al. 2013; Ron and Shamir 2014).

\section{Monetary theory and policy}

The fifth research stream explains $3.73 \%$ of the variance and consists of 10 articles plus three additional ones with high factor scores (cf. Table 7). The basic theme of the discourse is monetary theory, economics and policy. The network of authors is comparatively small. George Selgin and Randall Wright authored three publications, and William J. Luther contributed to four.

King (2016) provides an overview of the institutions of monetary policy but notes that his article raises more questions than it answers. The paper presents externalities in the theory of money and discusses the role of institutions. Finally, three case studies are presented, which serve to emphasize the importance of credible and stable institutions.

Selgin (2002) is the study with the highest factor loading (0.945) in the research stream. The article explores the implications of adaptive learning for monetary evolution using a search-theoretic framework. The author affirms the statement of Grossman (1991) that reconciliation of a theory with facts in monetary economics poses a significant problem, and 
Table 7 Articles on monetary theory and policy

\begin{tabular}{lll}
\hline Article & Factor loading & Factor score \\
\hline Selgin (2002) & 0.945 & 3.360 \\
Selgin (1994) & 0.943 & 3.590 \\
Kiyotaki and Wright (2016) & 0.942 & 2.630 \\
Li and Wright (1998) & 0.942 & 2.940 \\
King (2016) & 0.941 & 2.730 \\
Salter and Luther (2014) & 0.929 & 3.800 \\
Luther (2013) & 0.903 & 3.490 \\
Luther (2016) & 0.835 & 2.620 \\
Lagos and Wright (2005) & 0.757 & 0.890 \\
White (2015) & 0.719 & 2.370 \\
$\ldots$ & $\ldots$ & $\ldots$ \\
Selgin (2015) & 0.589 & 4.228 \\
Hendrickson et al. (2016) & 0.521 & 3.804 \\
Aiyagari and Wallace (1997) & 0.493 & 3.410 \\
\hline
\end{tabular}

This table shows factor loadings and factor scores of the most important publications assigned to research stream $\mathrm{V}$ (the fifth factor obtained through factor analysis)

Distribution across journals: two articles in The American Economic Review; one article each in The Economic Journal; Journal of Money, Credit and Banking; Journal of Economic Theory; Entangled Political Economy; Economic Affairs; The Independent Review; Journal of Political Economy; Cato Journal; Journal of Financial Stability; Economic Inquiry; Journal of Economic Theory.

introduces a formal monetary economics model that allows adaptive learning in a searchtheoretic framework. Other studies in the research stream also deal with search-theoretic models of money (Kiyotaki and Wright 2016; Li and Wright 1998). The article with the second highest factor loading (0.943) is also by Selgin (1994) and discusses whether, given monetary nationalism, nations have an incentive to establish their own currencies, which have no relation to an exchange rate of established money, through market interventions. Salter and Luther (2014) also discuss the role of governments in monetary policy and introduce a general theory of the appearance and perpetuation of money.

Besides economic analyses, the discourse also includes legal policy recommendations for dealing with digital currencies. White (2015) provides an overview of the market for digital currencies and explains that the market is still developing and full of surprises. He suggests that regulation should be very cautious, as interference in entrepreneurial discovery prevents potential breakthroughs that society does not yet know it misses (Kirzner 1985). Selgin (2015) discusses synthetic commodity money. Bitcoin is cited as an example and its underlying properties such as mining and emission are discussed against the background of monetary theory. The study has the highest factor score (4.228) and is therefore a major influence on the discourse. Similarly, Hendrickson et al. (2016), the study with the second highest factor score (3.804), explicitly analyze Bitcoin as a currency and, among other things, build an equilibrium model in which Bitcoin coexists with a governmentissued currency. 


\section{Social network analysis}

Having identified the most relevant research streams on blockchain and cryptocurrency in the areas of business and economics, the question arises how they are related. Social network analysis can serve to visualize the connections within and between the research streams. The results are shown in Fig. 3. The frequency of citation, a metric for the relevance of a publication, is represented by the size of the nodes. Each node is colored according to the research stream it is associated with, i.e. with respect to which it has a factor score of 0.4 or more. If a paper exceeds that value with respect to several factors, it is assigned where the factor score is greatest. The nodes (publications) are linked by a line in case of five or more co-citations.

The social network analysis yields conclusions about the state of research and the maturity of the streams. Streams III (transactions and anonymity) and IV (principles and applications of blockchain) use Nakamoto (2008) as their 'original source', as the discourses do not yet have their own intellectual midpoints, as evidenced by the very high factor scores of the Bitcoin whitepaper in the two streams. The whitepaper is best assigned to the second research stream (cf. Table 1). This stream has already developed considerably further, having produced several other prominent publications (e.g. Böhme et al. 2015; Ciaian et al. 2016; Dwyer 2015; Kristoufek 2013, 2015).

The most developed stream is No. I, market economics and efficiency. Its relationship to other streams is mostly limited to No. II, asset valuation and pricing. These two streams share a number of authors: Baur and Lucey (2010) and Baur and McDermott (2010) belong to stream II, while Baur et al. (2018a, b) belong to stream I. The field of monetary theory and implications is characterized by Selgin (2015), which is closely related to the research stream on asset valuation and price formation, and thus to the Bitcoin whitepaper. Many of the other publications clearly distance themselves thematically from the other research areas, which is also expressed, for example, by the very high factor loadings of the individual publications (see Table 7).

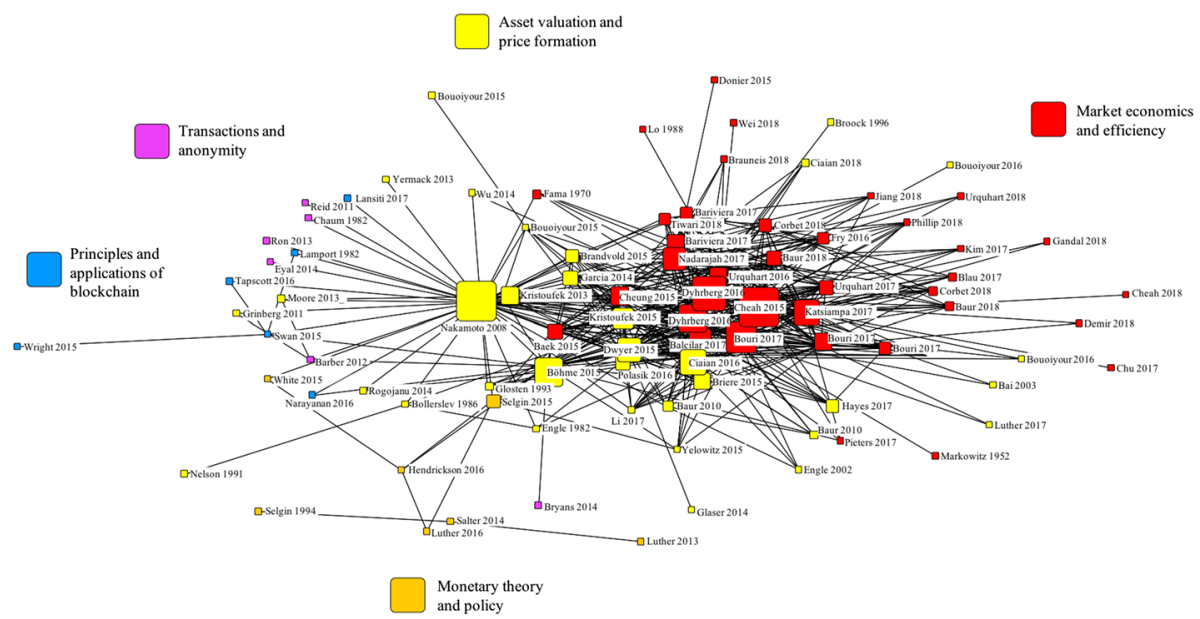

Fig. 3 Visualization of research stream interrelations. The size of a node represents the absolute number of citations, lines between articles represent five co-citations between articles. For readability, only relationships $\geq 5$ and only first authors are shown. Color represents research stream affiliation of nodes. Created with UCINET software 


\section{Discussion}

Blockchain and its manifestation cryptocurrency are basic technologies that entail a multitude of effects and vast potential for business models, corporate decisions and the economy. Researchers in this field have already generated substantial insights. Through factor analysis, five prominent research streams have been identified that are characterized by different studies. Since the technology has only existed since 2008, various other research streams can be expected to emerge in the future. Unsurprisingly, the results show Nakamoto (2008) to be a common core of several research streams. Nevertheless, it is already apparent that the progress of research is creating its own basis. Figure 3, for example, shows that among others Cheah and Fry (2015) and Dyhrberg (2016b) are located in the middle of the stream.

Various methods and economic theories are identified as formative literature. For example, GARCH models in stream II and economic theory in stream IV seem to be of high relevance. A partial absence, or rather wide spread across different methods and theories is observed, which can be an indication that the scientific discourse is still so young that researchers can apply a variety of methods. It is possible to refer to different theories. This may consolidate in the future if the streams continue to grow or split up into subcategories.

The first stream deals with the efficiency and economics of cryptocurrency markets and has already created its own scientific basis (cf. Figure 3). Fundamental theoretical contributions such as Fama (1970) or Markowitz (1952) are referenced but are not overly relevant for the discourse. This own basis largely comprises findings from the years 2015 to 2017, which could suggest that the field is developing rapidly (cf. Figure 2). Stream I is also characterized by a small but highly active group of authors, many of whom joined the field only recently. Logically, this results in numerous co-citations among these authors.

The second stream is best described as research on asset valuation and price formation. It is clearly related to the first stream, which is to be expected given the similarities between (financial) market behavior and price development in these markets. In Fig. 3, we see that stream II is concentrated at the center of the network and closely connected to stream I. In addition, a number of stream II publications are located in the outer parts of the network around streams I, III and IV. Only stream V has no articles close to its own network that can be assigned to the discourse of asset pricing. Questions about the prices or trading of cryptocurrency seem to be of universal relevance, which is why they interact with all other streams. Here again the question arises whether research stream II will split up in the near future. This seems likely, given the diversity of the articles. However, it should be pointed out that Nakamoto (2008), for example, only fits well with stream II. The whitepaper's factor loading of 0.487 with respect to stream II is also similar to what it is with respect to the first stream (0.456).

In the emerging field of blockchain principles and applications, original fundamental research is only just beginning to replace the Bitcoin whitepaper, which continues to be of great importance. At present, the outstanding articles of the stream consist of economic and technical fundamentals as well as introductory literature (in the form of books). Blockchain and cryptocurrencies are constantly changing, and the existing basic literature (e.g. Swan 2015; Tapscott and Tapscott 2018) may soon become outdated, if that has not already happened. The stream may split into various more specialised streams in the future, including application-specific streams.

While more developed discourses will have peer-reviewed articles as their formative works, this is not the case for research on blockchain and its application, nor for transactions and anonymity. Most publications in stream IV date from 2013/14, which may 
mean that most relevant findings were published then and scientific progress has slowed down. However, it is much more likely that this branch of research has been neglected (by peer-reviewed research). This does not necessarily apply to other scientific fields like computer science or engineering that have not been examined here. In this respect, there is an opportunity to gain a foothold within the stream and to shape its further development, for example through the systematic processing, review, presentation or transfer of the technical literature.

Research on monetary theory is a special field that differs strongly from the other discourses (see Fig. 3). The small number of authors indicates that the stream remains specialized. However, Selgin (2015) constitutes a meaningful connection to other discourses, while having great influence on the stream itself. The inflow of further researchers dealing with monetary theory and cryptocurrency may yield additional connections to other streams - a worthwhile opportunity for future research.

\section{Limitations}

This study is subject to some limitations, of which only the most relevant ones can be mentioned here. In line with common practice in the literature, the data were collected exclusively from the Web of Science. While many comparable databases exist, which might have yielded additional papers, they were not used for technical reasons (ease of data export). Furthermore, research on blockchain and cryptocurrencies is also published outside of peer-reviewed journals (cf. e.g. the seminal whitepapers). Therefore, it is likely that the search of the Web of Science will have missed some important contributions. Finally, the choice of search terms of course shaped the results and is open to debate.

\section{Future research avenues}

Figure 3 shows that streams one and two are already very dense and have an established scientific basis. Looking at the other streams, especially III and IV, plenty of space next to Nakamoto (2008) seems available. It seems plausible that the scientific basis for these streams has not yet been established, which can be interpreted as an opportunity for researchers to fill this space. The blockchain ecosystem is evolving rapidly.

Figure 2 shows very clearly that research on market economics and efficiency has increased dramatically in relation to the other areas since 2014. However, this is probêably due not only to the relevance of the topic but also to comparatively swift channels of publication (e.g. via research letters or notes). Research in the other streams should in principle be similarly far-reaching, which indicates potential research gaps.

Three of the five streams appear to still be developing, which suggests a wealth of starting points in these areas. While this article has focused on the sources underlying the 467 scientific publications, trends for future research can also be derived from this core sample of papers. Several research clusters within this set could develop into research streams in their own right. So far, there are no dedicated streams on application areas, management or entrepreneurship. If and when such streams arise, this will be a good opportunity for enterprising researchers.

The literature suggests that blockchain and cryptocurrency will have a big impact on financial services (Fanning and Centers 2016). Therefore, a separate stream may well form around potential applications in the financial sector, that bases on research stream 
III. Various applications are already being discussed in the literature, such as accounting, auditing, assurance or governance (Dai and Vasarhelyi 2017; Schmitz and Leoni 2019; Shermin 2017; Tan and Low 2019). Research on entrepreneurial finance like blockchain-based financing in the form of ICOs (Adhami et al. 2018; Ante et al. 2018; Drobetz et al. 2019; Fisch 2019) or individual investors in cryptocurrencies (Ante et al. 2020 ) is getting well underway. This research often refers to signaling theory (Spence 1973) and builds on the literature on crowdfunding (e.g. Agrawal et al. 2015; Ahlers et al. 2015; Mollick 2014), initial public offerings (e.g. Carter and Manaster 1990; Certo et al. 2001; Colombo et al. 2019) and venture capital (e.g. Ahlstrom and Bruton 2006). Within the framework of blockchain-based financing, future research potential abounds. On the one hand, the market for decentralized finance (DeFi) is constantly producing new mechanisms, such as initial exchange offerings (IEOs), initial dex offerings (IDOs) or security token offerings (STOs) (Ante and Fiedler 2019). On the other hand, the existing literature on financing, in particular crowdfunding and IPOs, forms a basis for various evaluation options and methods that can still be carried out for blockchain research. Niche aspects of financial markets, such as cross-listings (Ante and Meyer 2019; Meyer and Ante 2020), price manipulation (Gandal et al. 2018), money laundering (Ante 2018) or informed trading (Ante 2019; Feng et al. 2018), are only just starting to be addressed by the cryptocurrency literature.

Energy markets or smart grids and blockchain technology have been a big topic in engineering and computer science but are only now being researched in business science and economics. Green and Newman (2017) explain the potential of the blockchain in the energy sector, and Oh et al. (2017) show what blockchain technology can do for energy trading. Andoni et al. (2019) provide a general introduction to the wide-ranging potential and points to explore around blockchain and energy, including for example metering and billing, cryptocurrency-usage, decentralized (wholesale) trading, green certificates and grid management. A separate research stream will likely form around the field of energy, smart grids and decentralized markets. Other sectors on which scientists have recently published initial findings and which warrant significantly more research include the sharing economy (Pazaitis et al. 2017), the real estate economy (Veuger 2012), blockchain-based ownership structures (McConaghy et al. 2017), digital identity (Wolfond 2017), healthcare (Engelhardt 2017) and supply chain and provenance (Kim and Laskowski 2018).

Current developments around Facebook's crypto currency project Libra (Libra Association 2019) or the potential introduction of central bank digital currency (CBDC) by China (Reuters 2019) and other countries are likely to create much greater attention for research stream V. Economists have already begun to comment on Libra (e.g. Cecchetti and Schienholtz 2019; Eichengreen 2019), though not in peer-reviewed journals. The concept of socalled stable coins-blockchain tokens whose value is backed by fiat currencies or other assets such as gold-will for example find its way into monetary policy research and other research streams (e.g. Wei 2018b). Here, a differentiation can be made between decentralized protocols (e.g. makerdao.com) and stable coins issued by companies (e.g. tether.to). Against this background, a potential merging of research stream $\mathrm{V}$ with the other areas presents clear opportunities for researchers. 


\section{Conclusion}

This study has analysed the scientific basis of the existing literature in the field of blockchain technology and cryptocurrency using quantitative methodology, which enables a neutral and objective evaluation. Five research streams with the greatest thematic relevance were identified - two of which are already mature while three are still emerging — and their underlying content and approaches were presented. The results provide a basis for all researchers working within one of the five research streams. The identification of core publications in each sphere may serve as a starting point for new research endeavours. The interrelations between the discourses show that this young field of research still leaves a lot of room for manoeuvre, including fundamental original work. In other words, there is still ample space for scientific discovery next to Nakamoto (2008).

Acknowledgements Open Access funding provided by Projekt DEAL.

\section{Compliance with ethical standards}

Conflict of interest The authors declare that they have no conflict of interest.

Open Access This article is licensed under a Creative Commons Attribution 4.0 International License, which permits use, sharing, adaptation, distribution and reproduction in any medium or format, as long as you give appropriate credit to the original author(s) and the source, provide a link to the Creative Commons licence, and indicate if changes were made. The images or other third party material in this article are included in the article's Creative Commons licence, unless indicated otherwise in a credit line to the material. If material is not included in the article's Creative Commons licence and your intended use is not permitted by statutory regulation or exceeds the permitted use, you will need to obtain permission directly from the copyright holder. To view a copy of this licence, visit http://creativecommons.org/licenses/by/4.0/.

\section{References}

Adhami, S., Giudici, G., \& Martinazzi, S. (2018). Why do businesses go crypto? An empirical analysis of initial coin offerings. Journal of Economics and Business, 100, 64-75. https://doi.org/10.1016/j.jecon bus.2018.04.001.

Agrawal, A., Catalini, C., \& Goldfarb, A. (2015). Crowdfunding: geography, social networks, and the timing of investment decisions. Journal of Economics and Management Strategy, 24(2), 253-274. https ://doi.org/10.1111/jems.12093.

Ahlers, G. K., Cumming, D., Günther, C., \& Schweizer, D. (2015). Signaling in equity crowdfunding. Entrepreneurship Theory and Practice, 39(4), 955-980. https://doi.org/10.1111/etap.12157.

Ahlstrom, D., \& Bruton, G. D. (2006). Venture capital in emerging economies: networks and institutional change. Entrepreneurship Theory and Practice, 30(2), 299-320. https://doi.org/10.111 1/j.1540-6520.2006.00122.x.

Aiyagari, S. R., \& Wallace, N. (1997). Government transaction policy, the medium of exchange, and welfare. Journal of Economic Theory, 74(1), 1-18. https://doi.org/10.1006/jeth.1996.2250.

Alvarez-Ramirez, J., Rodriguez, E., \& Ibarra-Valdez, C. (2018). Long-range correlations and asymmetry in the Bitcoin market. Physica A: Statistical Mechanics and its Applications, 492, 948-955. https://doi. org/10.1016/j.physa.2017.11.025.

Andoni, M., Robu, V., Flynn, D., Abram, S., Geach, D., Jenkins, D., et al. (2019). Blockchain technology in the energy sector: A systematic review of challenges and opportunities. Renewable and Sustainable Energy Reviews, 100, 143-174. https://doi.org/10.1016/j.rser.2018.10.014.

Ante, L. (2018). Cryptocurrency, Blockchain and Crime. In K. McCarthy (Ed.), The Money Laundering Market: Regulating the Criminal Economy (pp. 171-198). Agenda Publishing. doi:10.2307/j. ctv $5 \operatorname{cg} 8 \mathrm{z} 1.10$

Ante, L. (2019). Market reaction to exchange listings of cryptocurrencies.. https://doi.org/10.13140/ RG.2.2.19924.76161. 
Ante, L., \& Fiedler, I. (2019). Cheap signals in security token offerings (STOs).. https://doi.org/10.2139/ ssrn.3356303.

Ante, L., Fiedler, I., von Meduna, M., \& Steinmetz, F. (2020). Returns from investing in cryptocurrency: evidence from german individual investors.. https://doi.org/10.2139/ssrn.3540876.

Ante, L., \& Meyer, A. (2019). Cross-listings of blockchain-based tokens issued through initial coin offerings: do liquidity and specific cryptocurrency exchanges matter? doi:10.13140/RG.2.2.27494.37442

Ante, L., Sandner, P., \& Fiedler, I. (2018). Blockchain-based ICOs: pure hype or the dawn of a new era of startup financing? Journal of Risk and Financial Management, 11(4), 80. https://doi.org/10.3390/ jrfm11040080.

Apte, S., \& Petrovsky, N. (2016). Will blockchain technology revolutionize excipient supply chain management? Journal of Excipients and Food Chemicals, 7(3), 76-78.

Aron, J. (2012). BitCoin software finds new life. New Scientist, 213(2847), 20.

Ashta, A., \& Biot-Paquerot, G. (2018). FinTech evolution: Strategic value management issues in a fast changing industry. Strategic Change, 27(4), 301-311. https://doi.org/10.1002/jsc.2203.

Atzori, M. (2017). Blockchain technology and decentralized governance: is the state still necessary? Journal of Governance and Regulation, 6(1), 1-37. https://doi.org/10.22495/jgr_v6_i1_p5.

Back, A. (2002). Hashcash - a denial of service counter-measure. www.hashcash.org/hashcash.pdf. Accessed 1 September 2019

Bariviera, A. F. (2017). The inefficiency of Bitcoin revisited: A dynamic approach. Economics Letters, 161, 1-4. https://doi.org/10.1016/j.econlet.2017.09.013.

Bariviera, A. F., Basgall, M. J., Hasperué, W., \& Naiouf, M. (2017). Some stylized facts of the Bitcoin market. Physica A: Statistical Mechanics and its Applications, 484, 82-90. https://doi.org/10.1016/j. physa.2017.04.159.

Batubara, F. R., Ubacht, J., \& Janssen, M. (2018). Challenges of Blockchain Technology Adoption for e-Government: A Systematic Literature Review. In Proceedings of the 19th Annual International Conference on Digital Government Research: Governance in the Data Age. ACM.

Baur, D. G., Dimpfl, T., \& Kuck, K. (2018a). Bitcoin, gold and the US dollar-A replication and extension. Finance Research Letters, 25, 103-110. https://doi.org/10.1016/j.frl.2017.10.012.

Baur, D. G., Hong, K. H., \& Lee, A. D. (2018b). Bitcoin: Medium of exchange or speculative assets? Journal of International Financial Markets, Institutions and Money, 54, 177-189. https://doi. org/10.1016/j.intfin.2017.12.004.

Baur, D. G., \& Lucey, B. M. (2010). Is gold a hedge or a safe haven? An analysis of stocks, bonds and gold. Financial Review, 45(2), 217-229. https://doi.org/10.1111/j.1540-6288.2010.00244.x.

Baur, D. G., \& McDermott, T. K. (2010). Is gold a safe haven? International evidence. Journal of Banking and Finance, 34(8), 1886-1898. https://doi.org/10.1016/j.jbankfin.2009.12.008.

Bayer, D., Haber, S., \& Stornetta, S. W. (1993). Improving the efficiency and reliability of digital timestamping. Sequences, II, 329-334. https://doi.org/10.1007/978-1-4613-9323-8_24.

Biehl, M., Kim, H., \& Wade, M. (2006). Relationships among the academic business disciplines: A multimethod citation analysis. Omega, 34(4), 359-371. https://doi.org/10.1016/j.omega.2004.12.002.

Böhme, R., Christin, N., Edelman, B., \& Moore, T. (2015). Bitcoin: economics, technology, and governance. Journal of Economic Perspectives, 29(2), 213-238. https://doi.org/10.1257/jep.29.2.213.

Borgatti, S. P., Everett, M. G., \& Freeman, L. C. (2002). Ucinet for Windows: Software for social network analysis. Harvard MA: analytical technologies, 6.

Bouoiyour, J., Aviral, R., Tiwari, K., \& Olayeni, O. R. (2016). What drives Bitcoin price? Economics Bulletin, 36(2), 843-850.

Bouoiyour, J., \& Selmi, R. (2015). What does Bitcoin look like? In Handbook of digital currency (pp. 31-43).

Bouri, E., Molnár, P., Azzi, G., Roubaud, D., \& Hagfors, L. I. (2017). On the hedge and safe haven properties of Bitcoin: Is it really more than a diversifier? Finance Research Letters, 20, 192-198. https ://doi.org/10.1016/j.frl.2016.09.025.

Brauneis, A., \& Mestel, R. (2018). Price discovery of cryptocurrencies: Bitcoin and beyond. Economics Letters, 165, 58-61. https://doi.org/10.1016/j.econlet.2018.02.001.

Bryans, D. (2014). Bitcoin and money laundering: mining for an effective solution. Indiana Law Journal, 89(1), 441-472.

Buterin, V. (2013). Ethereum White Paper - A Next Generation Smart Contract \& Decentralized Application Platform. https://blockchainlab.com/pdf/Ethereum_white_paper-a_next_generation_smart _contract_and_decentralized_application_platform-vitalik-buterin.pdf

Carrington, P. J., Scott, J., \& Wassermann, S. (2005). Models and methods in social network analysis. New York, NY: Cambridge University Press. 
Carter, R., \& Manaster, S. (1990). Initial public offerings and underwriter reputation. The Journal of Finance, 45(4), 1045-1067. https://doi.org/10.1111/j.1540-6261.1990.tb02426.x.

Castro, M., \& Liskov, B. (1999). Practical byzantine fault tolerance. OSDI, 99, 173-186.

Caytas, J. D. (2016). Developing blockchain real-time clearing and settlement in the EU, U.S., and globally.

Cecchetti, S., \& Schienholtz, K. (2019). Libra: A dramatic call to regulatory action. VOX CEPR Policy Portal. Retrieved 31 Aug 2019 from: https://voxeu.org/article/libra-dramatic-call-regulatory-actio n.

Certo, S. T., Daily, C. M., \& Dalton, D. R. (2001). Signaling firm value through board structure: an investigation of initial public offerings. Entrepreneurship Theory and Practice, 26(2), 33-50. https ://doi.org/10.1177/104225870102600202.

Chaum, D. (2012). Advances in Cryptology: proceedings of Crypto. Springer Science \& Business Media.

Cheah, E. T., \& Fry, J. (2015). Speculative bubbles in Bitcoin markets? An empirical investigation into the fundamental value of Bitcoin. Economics Letters, 130, 32-36.

Cheah, E. T., Mishra, T., Parhi, M., \& Zhang, Z. (2018). Long memory interdependency and inefficiency in Bitcoin markets. Economics Letters, 167, 18-25. https://doi.org/10.1016/j.econlet.2018.02.010.

Chen, Y., \& Leimkuhler, F. F. (1986). A relationship between Lotka's Law, Bradford's Law, and Zipf's Law. Journal of the American Society for Information Science, 37(5), 307-314.

Chen, Z., Li, Y., Wu, Y., \& Luo, J. (2017). The transition from traditional banking to mobile internet finance: an organizational innovation perspective - a comparative study of Citibank and ICBC. Financial Innovation, 3(1), 1-6. https://doi.org/10.1186/s40854-017-0062-0.

Chiu, J., \& Koeppl, T. V. (2019). Blockchain-based settlement for asset trading. The Review of Financial Studies, 32(5), 1716-1753. https://doi.org/10.1093/rfs/hhy122.

Ciaian, P., Rajcaniova, M., \& Kancs, D. (2016). The economics of BitCoin price formation. Applied Economics, 48(19), 1799-1815. https://doi.org/10.1080/00036846.2015.1109038.

Ciaian, P., Rajcaniova, M., \& Kancs, D. (2018). Virtual relationships: Short- and long-run evidence from BitCoin and altcoin markets. Journal of International Financial Markets, Institutions and Money, 52, 173-195. https://doi.org/10.1016/j.intfin.2017.11.001.

Coase, R. H. (1937). The nature of the firm. Econometrica, 4(16), 386-405. https://doi.org/10.1093/ oxfordjournals.jleo.a036946.

Cocco, L., Pinna, A., \& Marchesi, M. (2017). Banking on blockchain: Costs savings thanks to the blockchain technology. Future Internet, 9(3), 1-20. https://doi.org/10.3390/fi9030025.

Colombo, M. G., Meoli, M., \& Vismara, S. (2019). Signaling in science-based IPOs: The combined effect of affiliation with prestigious universities, underwriters, and venture capitalists. Journal of Business Venturing, 34(1), 141-177.

Conoscenti, M., Vetro, A., \& De Martin, J. C. (2017). Blockchain for the Internet of Things: A systematic literature review. In Proceedings of IEEE/ACS International Conference on Computer Systems and Applications, AICCSA (pp. 1-6). IEEE. doi:10.1109/AICCSA.2016.7945805

Corbet, S., Lucey, B., Urquhart, A., \& Yarovaya, L. (2019). Cryptocurrencies as a financial asset: A systematic analysis. International Review of Financial Analysis, 62, 182-199. https://doi. org/10.1016/j.irfa.2018.09.003.

Corbet, S., Lucey, B., \& Yarovaya, L. (2018a). Datestamping the Bitcoin and Ethereum bubbles. Finance Research Letters, 26, 81-88. https://doi.org/10.1016/j.frl.2017.12.006.

Corbet, S., Meegan, A., Larkin, C., Lucey, B., \& Yarovaya, L. (2018b). Exploring the dynamic relationships between cryptocurrencies and other financial assets. Economics Letters, 165, 28-34. https:// doi.org/10.1016/j.econlet.2018.01.004.

Dabbagh, M., Sookhak, M., \& Safa, N. S. (2019). The evolution of blockchain: A bibliometric study. IEEE Access, 7, 19212-19221. https://doi.org/10.1109/ACCESS.2019.2895646.

Dai, J., \& Vasarhelyi, M. A. (2017). Toward blockchain-based accounting and assurance. Journal of Information Systems. https://doi.org/10.2308/isys-51804.

Dai, W. (1998). b-money. Retrieved 9 Sep 2019 from: www.weidai.com/bmoney.txt.

DiStefano, C., Zhu, M., \& Mîndrilă, D. (2009). Understanding and using factor scores: Considerations for the applied researcher. Practical Assessment, Research and Evaluation, 14(1), 20.

Donier, J., \& Bouchaud, J. P. (2015). Why do markets crash? Bitcoin data offers unprecedented insights. PLoS ONE, 10(10), 23-25. https://doi.org/10.1371/journal.pone.0139356.

Drobetz, W., Momtaz, P. P., \& Schröder, H. (2019). Investor sentiment and initial coin offerings. The Journal of Alternative Investments, 21(4), 41-55. https://doi.org/10.3905/jai.2019.1.069.

Dunphy, P., \& Petitcolas, F. A. P. (2018). A first look at identity management schemes on the blockchain. IEEE Security and Privacy, 16(4), 20-29. https://doi.org/10.1109/MSP.2018.3111247. 
Dwork, C., \& Naor, M. (1992). Pricing via processing or combatting junk mail. Annual International Cryptology Conference (pp. 139-147). Berlin, Heidelberg: Springer.

Dwyer, G. P. (2015). The economics of Bitcoin and similar private digital currencies. Journal of Financial Stability, 17, 81-91. https://doi.org/10.1016/j.jfs.2014.11.006.

Dyhrberg, A. H. (2016a). Bitcoin, gold and the dollar - A GARCH volatility analysis. Finance Research Letters, 16, 85-92. https://doi.org/10.1016/j.frl.2015.10.008.

Dyhrberg, A. H. (2016b). Hedging capabilities of bitcoin. Is it the virtual gold? Finance Research Letters, 16, 139-144. https://doi.org/10.1016/j.frl.2015.10.025.

Eichengreen, B. (2019). Libra: The known unknown and unknown unkowns. VOX CEPR Policy Portal. Retrieved 8 Sep 2019 from: https://voxeu.org/article/libra-known-unknowns-and-unknown-unkno wns.

Engelhardt, M. A. (2017). Hitching healthcare to the chain: an introduction to blockchain technology in the healthcare sector. Technology Innovation Management Review, 7(10), 22-34. https://doi. org/10.22215/timreview/1111.

Engle, R. (2002). Dynamic conditional correlation: A simple class of multivariate generalized autoregressive conditional heteroskedasticity models. Journal of Business and Economic Statistics, 20(3), 339-350. https://doi.org/10.1198/073500102288618487.

Esposito, C., De Santis, A., Tortora, G., Chang, H., \& Choo, K. K. R. (2018). Blockchain: A panacea for healthcare cloud-based data security and privacy? IEEE Cloud Computing, 5(1), 31-37. https:// doi.org/10.1109/MCC.2018.011791712.

Eyal, I., \& Sirer, E. G. (2014). Majority Is Not Enough: Bitcoin mining is vulnerable. In Eighteenth International Conference on Financial Cryptography and Data Security.

Fama, E. F. (1970). Efficient capital markets: A review of theory and empirical work. The Journal of Finance, 25(2), 383-417. https://doi.org/10.2307/2325486.

Fanning, K., \& Centers, D. P. (2016). Blockchain and its coming impact on financial services. Journal of Corporate Accounting and Finance, 27(5), 53-57. https://doi.org/10.1002/jcaf.

Feng, W., Wang, Y., \& Zhang, Z. (2018). Informed trading in the Bitcoin market. Finance Research Letters, 26, 63-70. https://doi.org/10.1016/j.frl.2017.11.009.

Fiedler, I., Ante, L., Steinmetz, F., \& Häseler, S. (2018). Distributed Ledger Technology: A Possible Way Forward for Securities Clearing. Binary District. Retrieved 8 Sep 2019 from: https://journ al.binarydistrict.com/distributed-ledger-technology-a-possible-way-forward-for-securities-clear ing/.

Firdaus, A., Razak, M. F. A., Feizollah, A., Hashem, I. A. T., Hazim, M., \& Anuar, N. B. (2019). The rise of "blockchain": bibliometric analysis of blockchain study. Scientometrics, 120(3), 1289_ 1331. https://doi.org/10.1007/s11192-019-03170-4.

Fisch, C. (2019). Initial coin offerings (ICOs) to finance new ventures. Journal of Business Venturing, 34(1), 1-22. https://doi.org/10.1016/j.jbusvent.2018.09.007.

Francisco, K., \& Swanson, D. (2018). The supply chain has no clothes: technology adoption of blockchain for supply chain transparency. Logistics, 2(1), 2. https://doi.org/10.3390/logistics2010002.

Fry, J., \& Cheah, E. T. (2016). Negative bubbles and shocks in cryptocurrency markets. International Review of Financial Analysis, 47, 343-352. https://doi.org/10.1016/j.irfa.2016.02.008.

Gandal, N., Hamrick, J. T., Moore, T., \& Oberman, T. (2018). Price manipulation in the Bitcoin ecosystem. Journal of Monetary Economics, 95, 86-96. https://doi.org/10.1016/j.jmoneco.2017.12.004.

Gkillas, K., \& Katsiampa, P. (2018). An application of extreme value theory to cryptocurrencies. Economics Letters, 164, 109-111. https://doi.org/10.1016/j.econlet.2018.01.020.

Glosten, L. R., Jagannathan, R., \& Runkle, D. E. (1993). On the relation between the expected value and the volatility of the nominal excess return on stocks. The Journal of Finance, 48(5), 1779-1801.

Gomber, P., Kauffman, R. J., Parker, C., \& Weber, B. W. (2018). On the fintech revolution: interpreting the forces of innovation, disruption, and transformation in financial services. Journal of Management Information Systems, 35(1), 220-265. https://doi.org/10.1080/07421222.2018.1440766.

Gorsuch, R. L. (1988). Exploratory Factor Analysis. In J. R. Nesselroade \& R. B. Cattell (Eds.), Handbook of Multivariate Experimental Psychology (pp. 231-258). Boston, MA: Springer, US. https://doi. org/10.1007/978-1-4613-0893-5_6.

Governatori, G., Idelberger, F., Milosevic, Z., Riveret, R., Sartor, G., \& Xu, X. (2018). On legal contracts, imperative and declarative smart contracts, and blockchain systems. Artificial Intelligence and Law, 26(4), 377-408.

Green, J., \& Newman, P. (2017). Citizen utilities: The emerging power paradigm. Energy Policy, 105(March), 283-293. https://doi.org/10.1016/j.enpol.2017.02.004.

Grossman, H. (1991). Monetary Economics - A Review Essay. National Bureau of Economic Research. 
Guo, Y., \& Liang, C. (2016). Blockchain application and outlook in the banking industry. Financial Innovation, 2(1), 24. https://doi.org/10.1186/s40854-016-0034-9.

Haber, S., \& Stornetta, S. W. (1990). How to time-stamp a digital document. Conference on the Theory and Application of Cryptography (pp. 437-455). Berlin, Heidelberg: Springer.

Haber, S., \& Stornetta, S. W. (1997). Secure names for bit-strings. Proceedings of the ACM Conference on Computer and Communications Security, 28-35.

Harris, L. (1991). Stock price clustering and discreteness. Review of Financial Studies, 4, 389-415.

Hawlitschek, F., Notheisen, B., \& Teubner, T. (2018). The limits of trust-free systems: A literature review on blockchain technology and trust in the sharing economy. Electronic Commerce Research and Applications, 29, 50-63. https://doi.org/10.1016/j.elerap.2018.03.005.

Hayes, A. S. (2017). Cryptocurrency value formation: An empirical study leading to a cost of production model for valuing bitcoin. Telematics and Informatics, 34(7), 1308-1321. https://doi.org/10.1016/j. tele.2016.05.005.

Hendrickson, J. R., Hogan, T. L., \& Luther, W. J. (2016). The political economy of bitcoin. Economic Inquiry, 54(2), 925-939. https://doi.org/10.1111/ecin.12291.

Holub, M., \& Johnson, J. (2018). Bitcoin research across disciplines. Information Society, 34(2), 114-126. https://doi.org/10.1080/01972243.2017.1414094.

Hurst, H. E. (1951). Long-term storage capacity of reservoirs. Transactions of the American Society of Civil Engineers, 116, 770-808.

Iansiti, M., \& Lakhani, H. (2017). The truth about blockchain. Harvard Business Review, 95(1), 118-127.

Jensen, M. C., \& Meckling, W. H. (1976). Theory of the firm managerial behaviour, ageny costs and ownership structure. Journal of Financial Economics, 3, 305-360.

Kaiser, H. F. (1959). Computer program for varimax rotation in factor analysis. Educational and Psychological Measurement, 19(3), 413-420. https://doi.org/10.1177/001316445901900314.

Karafiloski, E., \& Mishev, A. (2017). Blockchain solutions for big data challenges: A literature review. In 17th IEEE International Conference on Smart Technologies, EUROCON 2017 - Conference Proceedings (pp. 763-768). doi:10.1109/EUROCON.2017.8011213

Katsiampa, P. (2017). Volatility estimation for Bitcoin: A comparison of GARCH models. Economics Letters, 158, 3-6. https://doi.org/10.1016/j.econlet.2017.06.023.

Khan, M. A., \& Salah, K. (2018). IoT security: Review, blockchain solutions, and open challenges. Future Generation Computer Systems, 82, 395-411. https://doi.org/10.1016/j.future.2017.11.022.

Kim, H. M., \& Laskowski, M. (2018). Toward an ontology-driven blockchain design for supply-chain provenance. Intelligent Systems in Accounting, Finance and Management, 25(1), 18-27. https://doi. org/10.1002/isaf.1424.

Kim, S., \& Sarin, A. (2019). Distributed ledger and blockchain technology: framework and use cases. Journal of Investment Management. https://doi.org/10.2139/ssrn.3373347.

Kim, T. (2017). On the transaction cost of Bitcoin. Finance Research Letters, 23, 300-305. https://doi. org/10.1016/j.frl.2017.07.014.

King, M. (2016). The institutions of monetary policy. The American Economic Review, 94(2), 1-13. https:// doi.org/10.1257/0002828041301957.

Kirzner, I. M. (1985). The Perils of Regulation: A Market-Process Approach. In Discovery and the Capitalist Process. Chicago: University of Chicago Press.

Kiyotaki, B. N., \& Wright, R. (2016). A search-theoretic approach to monetary economics. The American Economic Review, 83(1), 63-77.

Klarin, A. (2020). The decade-long cryptocurrencies and the blockchain rollercoaster: Mapping the intellectual structure and charting future directions. Research in International Business and Finance, 51, 101067. https://doi.org/10.1016/j.ribaf.2019.101067.

Kristoufek, L. (2013). BitCoin meets Google Trends and Wikipedia: Quantifying the relationship between phenomena of the Internet era. Scientific Reports, 3, 1-7. https://doi.org/10.1038/srep03415.

Kristoufek, L. (2015). What are the main drivers of the bitcoin price? Evidence from wavelet coherence analysis. PLoS ONE, 10(4), 1-15. https://doi.org/10.1371/journal.pone.0123923.

Kristoufek, L. (2018). On Bitcoin markets (in)efficiency and its evolution. Physica A: Statistical Mechanics and its Applications, 503, 257-262. https://doi.org/10.1016/j.physa.2018.02.161.

Krugman, P. (2013). Bitcoin Is Evil. The New York Times. Retrieved 4 Sep 2019 from: https//krugman. blogs.nytimes.com/2013/12/28/bitcoin-is-evil/.

Kuntner, T., \& Teichert, T. (2016). The scope of price promotion research: An informetric study. Journal of Business Research, 69(8), 2687-2696. https://doi.org/10.1016/j.jbusres.2015.11.004.

Lagos, R., \& Wright, R. (2005). A unified framework for monetary theory and policy analysis. Journal of Political Economy, 113(3), 463-484. https://doi.org/10.1086/429804. 
Lahmiri, S., Bekiros, S., \& Salvi, A. (2018). Long-range memory, distributional variation and randomness of bitcoin volatility. Chaos, Solitons and Fractals, 107, 43-48. https://doi.org/10.1016/j.chaos .2017.12.018

Lamport, L., Shostak, R., \& Pease, M. (1982). The Byzantine generals problem. ACM Transactions on Programming Languages and Systems (TOPLAS), 4(3), 382-401.

Li, Y., \& Wright, R. (1998). Government transaction policy, media of exchange, and prices. Journal of Economic Theory, 81(2), 290-313. https://doi.org/10.1006/jeth.1997.2363.

Liang, X., Zhao, J., Shetty, S., Liu, J., \& Li, D. (2018). Integrating blockchain for data sharing and collaboration in mobile healthcare applications. IEEE International Symposium on Personal, Indoor and Mobile Radio Communications, PIMRC, 2017-October, 1-5. doi:10.1109/PIMRC.2017.8292361

Libra Association. (2019). An Introduction to Libra. Retrieved 15 Sep 2019 from: https://libra.org/en-US/ wp-content/uploads/sites/23/2019/06/LibraWhitePaper_en_US.pdf.

Liu, J. (2016). Bitcoin Literature: a Co-Word Analysis. In 6th Economics \& Finance Conference, OECD: Paris (pp. 262-272). doi:10.20472/efc.2016.006.013

Luther, W. J. (2013). Friedman versus Hayek on private outside monies: New evidence for the debate. Economic Affairs, 33(1), 127-135. https://doi.org/10.1111/ecaf.12001.

Luther, W. J. (2016). Bitcoin and the future of digital payments. The Independent Review, 20(3), $397-404$.

Markowitz, H. (1952). Portfolio selection. The Journal of Finance, 7(1), 77-91.

Massias, H., Avila, X. S., \& Quisquater, J. J. (1999). Design of a secure timestamping service with minimal trust requirement. In The 20th Symposium on Information Theory in the Benelux.

Maurer, B., Nelms, T. C., \& Swartz, L. (2013). When perhaps the real problem is money itself!: The practical materiality of Bitcoin. Social Semiotics, 23(2), 261-277. https://doi.org/10.1080/10350 330.2013.777594.

McCain, K. W. (1990). Mapping authors in intellectual space: A technical overview. Journal of the American Society for Information Science, 41(6), 433-443. https://doi.org/10.1002/(SICI)1097-4571(19900 9)41:6\%3c433:AID-ASI11\%3e3.0.CO;2-Q.

McConaghy, M., McMullen, G., Parry, G., McConaghy, T., \& Holtzman, D. (2017). Visibility and digital art: Blockchain as an ownership layer on the Internet. Strategic Change, 26(5), 461-470. https://doi. $\operatorname{org} / 10.1002 /$ jsc. 2146.

Meiklejohn, S., Pomarole, M., Jordan, G., Levchenko, K., McCoy, D., Voelker, G. M., \& Savage, S. (2013). A fistful of Bitcoins: Characterizing payments among men with no names. In Proceedings of the 2013 conference on Internet measurement conference. ACM (pp. 127-140). doi:10.1145/2896384

Merediz-Solá, I., \& Bariviera, A. F. (2019). A bibliometric analysis of bitcoin scientific production. Research in International Business and Finance, 50(June), 294-305. https://doi.org/10.1016/j.ribaf .2019.06.008

Merkle, R. C. (1980). Protocols for public key cryptosystems. Proceedings - IEEE Symposium on Security and Privacy, 122-134, https://doi.org/10.1109/SP.1980.10006.

Meyer, A., \& Ante, L. (2020). Effects of initial coin offering characteristics on cross-listing returns.. https:// doi.org/10.13140/RG.2.2.10972.33920.

Miau, S., \& Yang, J. M. (2018). Bibliometrics-based evaluation of the Blockchain research trend: 2008March 2017. Technology Analysis and Strategic Management, 30(9), 1029-1045. https://doi. org/10.1080/09537325.2018.1434138.

Miller, M. (1997). The Future of Law. In paper delivered at the Extro (p. 3).

Mollick, E. R. (2014). The dynamics of crowdfunding: An exploratory study. Journal of Business Venturing, 29(1), 1-16. https://doi.org/10.1016/j.jbusvent.2013.06.005.

Nadarajah, S., \& Chu, J. (2017). On the inefficiency of Bitcoin. Economics Letters, 150, 6-9. https://doi. org/10.1016/j.econlet.2016.10.033.

Nakamoto, S. (2008). Bitcoin: A Peer-to Peer Electronic Cash System. Retrieved 12 June 2019 from: https ://bitcoin.org/bitcoin.pdf.

Nerur, S. P., Rasheed, A. A., \& Natarajan, V. (2008). The intellectual structure of the strategic management field: An author co-citation analysis. Strategic Management Journal, 29(3), 319-336. https:// doi.org/10.1002/smj.659.

O'Shields, R. (2017). Smart contracts: Legal agreements for the blockchain. North Carolina Banking Institute, 21(1), 177-194.

Ober, M., Katzenbeisser, S., \& Hamacher, K. (2013). Structure and anonymity of the bitcoin transaction graph. Future Internet, 5(2), 237-250. https://doi.org/10.3390/fi5020237.

Oh, S.-C., Kim, M.-S., Park, Y., Roh, G.-T., \& Lee, C.-W. (2017). Implementation of blockchain-based energy trading system. Asia Pacific Journal of Innovation and Entrepreneurship, 11(3), 322-334. https://doi. org/10.1108/apjie-12-2017-037. 
Ølnes, S., Ubacht, J., \& Janssen, M. (2017). Blockchain in government: Benefits and implications of distributed ledger technology for information sharing. Government Information Quarterly, 34(3), 355-364. https:// doi.org/10.1016/j.giq.2017.09.007.

Pazaitis, A., De Filippi, P., \& Kostakis, V. (2017). Blockchain and value systems in the sharing economy: The illustrative case of Backfeed. Technological Forecasting and Social Change, 125, 105-115. https://doi. org/10.1016/j.techfore.2017.05.025.

Persson, O., Danell, R., \& Schneider, J. W. (2009). How to use Bibexcel for various types of bibliometric analysis. Celebrating scholarly communication studies: A Festschrift for Olle Persson at his 60th Birthday, 9-24. https://lup.lub.lu.se/record/1458990/file/1458992.pdf

Phillip, A., Chan, J., \& Peiris, S. (2018). A new look at cryptocurrencies. Economics Letters, 163, 6-9. https:// doi.org/10.1016/j.econlet.2017.11.020.

Reid, F., \& Harrigan, M. (2013). An analysis of anonymity in the bitcoin system. Security and Privacy in Social Networks, 197-223, https://doi.org/10.1007/978-1-4614-4139-7_10.

Reuters. (2019). China says new digital currency will be similar to Facebook's Libra. Reuters. Retrieved 4 Sep 2019 from: www.reuters.com/article/us-china-cryptocurrency-cenbank/china-says-new-digital-currencywill-be-similar-to-facebooks-libra.

Rogojanu, A., \& Badea, L. (2014). The issue of competing currencies: Case study-Bitcoin. Theoretical and Applied Economics, 21(1), 103-114.

Ron, D., \& Shamir, A. (2014). Quantitative Analysis of the Full Bitcoin Transaction Graph. In International Conference on Financial Cryptography and Data Security. Springer: Berlin, Heidelberg. doi:10.1007/978-3-642-39884-1

Salmerón-Manzano, E., \& Manzano-Agugliaro, F. (2019). The role of smart contracts in sustainability: Worldwide research trends. Sustainability, 11(11), 3049. https://doi.org/10.3390/su11113049.

Salter, A. W., \& Luther, W. J. (2014). Synthesizing state and spontaneous order theories of money. In Entangled Political Economy (pp. 161-178). Emerald Group Publishing Limited.

Schmitz, J., \& Leoni, G. (2019). Accounting and auditing at the time of blockchain technology: A research agenda. Australian Accounting Review, 29(2), 331-342. https://doi.org/10.1111/auar.12286.

Seebacher, S., \& Schüritz, R. (2017). Blockchain technology as an enabler of service systems: A structured literature review. International Conference on Exploring Services Science (pp. 12-23). Cham: Springer. https://doi.org/10.1007/978-3-319-56925-3_2.

Selgin, G. (1994). On ensuring the acceptability of a new fiat money. Journal of Money, Credit and Banking, 26(4), 808-826. https://doi.org/10.2307/2077948.

Selgin, G. (2002). Adaptive learning and the transition to fiat money. The Economic Journal, 113(484), 147165. https://doi.org/10.1111/1468-0297.00094.

Selgin, G. (2015). Synthetic commodity money. Journal of Financial Stability, 17, 92-99. https://doi. org/10.1016/j.jfs.2014.07.002.

Shermin, V. (2017). Disrupting governance with blockchains and smart contracts. Strategic Change, 26(5), 499-509. https://doi.org/10.1002/jsc.2150.

Small, H. G. (1973). Co-citation in the scientific literature: A new measure of the relationship between two documents. Journal of the American Society for Information Science, 24, 265-269. https://doi.org/10.1002/ asi.4630240406.

Small, H. G. (1977). A co-citation model of a scientific specialty: A longitudinal study of collagen research. Social Studies of Science, 7(2), 139-166. https://doi.org/10.1177/030631277700700202.

Spence, M. (1973). Job market signaling. The Quarterly Journal of Economics, 87(3), 355-374. https://doi. org/10.1055/s-2004-820924.

Sprankel, S. (2013). Technical Basis of Digital Currencies. www.coderblog.de/wp-content/uploads/technicalbasis-of-digital-currencies.pdf

Stokes, R. (2012). Virtual money laundering: The case of Bitcoin and the Linden dollar. Information and Communications Technology Law, 21(3), 221-236. https://doi.org/10.1080/13600834.2012.744225.

Sun, J., Yan, J., \& Zhang, K. Z. K. (2016). Blockchain-based sharing services: What blockchain technology can contribute to smart cities. Financial Innovation, 2(1), 1-9. https://doi.org/10.1186/s40854-016-0040-y.

Swan, M. (2015). Blockchain: Blueprint for a new economy. O’Reilly Media, Inc.

Szabo, N. (1997). Formalizing and Securing Relationships on Public Networks. First Monday, 2(9). doi:10.5210/fm.v2i9.548

Tan, B. S., \& Low, K. Y. (2019). Blockchain as the database engine in the accounting system. Australian Accounting Review, 29(2), 312-318. https://doi.org/10.1111/auar.12278.

Tapscott, D., \& Tapscott, A. (2018). Blockchain revolution: How the technology behind bitcoin and other cryptocurrencies is changing the world. Portfolio. 
Taylor, P. J., Dargahi, T., Dehghantanha, A., Parizi, R. M., \& Choo, K. K. R. (2019). A systematic literature review of blockchain cyber security. Digital Communications and Networks, (June 2018). doi:10.1016/j. dcan.2019.01.005

The Economist. (2015). The Trust Machine. www.economist.com/leaders/2015/10/31/the-trust-machine

Tiwari, A. K., Jana, R. K., Das, D., \& Roubaud, D. (2018). Informational efficiency of Bitcoin - An extension. Economics Letters, 163, 106-109. https://doi.org/10.1016/j.econlet.2017.12.006.

Tranfield, D., Denyer, D., \& Smart, P. (2003). Towards a methodology for developing evidence-informed management knowledge by means of systematic review. British Journal of Management, 14(3), 207-222. https://doi.org/10.1111/1467-8551.00375.

Tsai, W. T., Deng, E., Ding, X., \& Li, J. (2018). Application of blockchain to trade clearing. In 2018 IEEE 18th International Conference on Software Quality, Reliability, and Security Companion (pp. 154-163). IEEE. doi:10.1109/QRS-C.2018.00039

Urquhart, A. (2016). The inefficiency of Bitcoin. Economics Letters, 148, 80-82.

Urquhart, A. (2017). Price clustering in Bitcoin. Economics Letters, 159, 145-148. https://doi.org/10.1016/j. econlet.2017.07.035.

Urquhart, A. (2018). What causes the attention of Bitcoin? Economics Letters, 166, 40-44. https://doi. org/10.1016/j.econlet.2018.02.017.

Veuger, J. (2012). Trust in a viable real estate economy with disruption and blockchain. Facilities, 36(1/2), 103-120.

Vishnumurthy, V., Chandrakumar, S., \& Sirer, E. G. (2003). Karma: A secure economic framework for peer-topeer resource sharing. Workshop on Economics of Peer-to-peer Systems, 35(6).

Wei, W. C. (2018a). Liquidity and market efficiency in cryptocurrencies. Economics Letters, 168, 21-24. https:// doi.org/10.1016/j.econlet.2018.04.003.

Wei, W. C. (2018b). The impact of Tether grants on Bitcoin. Economics Letters, 171, 19-22. https://doi. org/10.1016/j.econlet.2018.07.001.

White, L. H. (2015). The market for cryptocurrencies. Cato Journal, 35(2), 383-402.

Wolfond, G. (2017). A Blockchain ecosystem for digital identity: improving service delivery in Canada's public and private sectors. Technology Innovation Management Review, 7(10), 35-40. https://doi.org/10.22215 /timreview/1112.

Wood, G. (2014). Ethereum: a secure decentralised generalised transaction ledger. https://ethereum.github.io/ yellowpaper/paper.pdf

Wörfel, P. (2019). Unravelling the intellectual discourse of implicit consumer cognition : A bibliometric review. Journal of Retailing and Consumer Services, (September), 101960. https://doi.org/10.1016/j.jretconser .2019 .101960

Wright, A., \& De Filippi, P. (2015). Decentralized blockchain technology and the rise of lex cryptographia.. https://doi.org/10.2139/ssrn.2580664.

Yang, D., \& Li, M. (2018). Evolutionary approaches and the construction of technology-driven regulations. Emerging Markets Finance and Trade, 54(14), 3256-3271. https://doi.org/10.1080/15404 96X.2018.1496422.

Yermack, D. (2015). Is Bitcoin a real currency? Handbook of Digital Currency. https://doi.org/10.2139/ ssrn.2361599.

Yli-Huumo, J., Ko, D., Choi, S., Park, S., \& Smolander, K. (2016). Where is current research on Blockchain technology? - A systematic review. PLoS ONE, 11(10), 1-27. https://doi.org/10.1371/journal.pone.01634 77.

Yonghong, J., He, N., \& Weihua, R. (2018). Time-varying long-term memory in Bitcoin market. Finance Research Letters, 25, 280-284. https://doi.org/10.1016/j.frl.2017.12.009.

Yue, X., Wang, H., Jin, D., Li, M., \& Jiang, W. (2016). Healthcare data gateways: found healthcare intelligence on blockchain with novel privacy risk control. Journal of Medical Systems, 40(10), 218.

Zeng, S., Ni, X., Yuan, Y., \& Wang, F. Y. (2018). A Bibliometric Analysis of Blockchain Research. In IEEE Intelligent Vehicles Symposium, Proceedings (pp. 102-107). IEEE. doi:10.1109/IVS.2018.8500606

Zupic, I., \& Čater, T. (2015). Bibliometric methods in management and organization. Organizational Research Methods, 18(3), 429-472. https://doi.org/10.1177/1094428114562629.

Zuschke, N. (2019). An analysis of process-tracing research on consumer decision-making. Journal of Business Research, 1-16, https://doi.org/10.1016/j.jbusres.2019.01.028.

Zyskind, G., Nathan, O., \& Pentland, A. S. (2015). Decentralizing privacy: Using blockchain to protect personal data. In Proceedings - 2015 IEEE Security and Privacy Workshops, SPW 2015 (pp. 180-184). doi:10.1109/SPW.2015.27 